Artigo

\title{
Impacto da Assimilação de Perfis de Refratividade do Satélite Metop-B nas Previsões de Tempo do CPTEC/INPE Durante os Meses de Janeiro e Agosto de 2014
}

\author{
Ivette Hernández Banos ${ }^{1}$ iD, Luiz Fernando Sapucci² iD, Lucas Amarante Avanço² iD, \\ Fábio Luiz Rodrigues Diniz ${ }^{1}$ iD \\ ${ }^{1}$ Programa de Pós-Graduação em Meteorologia, Instituto Nacional de Pesquisas Espaciais, \\ São José dos Campos, SP, Brasil. \\ ${ }^{2}$ Centro de Previsão de Tempo e Estudos Climáticos, Instituto Nacional de Pesquisas Espaciais, \\ Cachoeira Paulista, SP, Brasil.
}

Recebido em 23 de Março de 2017 - Aceito em 22 de Agosto de 2017

\begin{abstract}
Resumo
Atualmente tem crescido o número de satélites de órbita baixa dedicados à rádio ocultação dos sinais do Sistema de Posicionamento Global (GPS). O MetOp-B é um desses novos satélites, mas ainda não foi explorado na assimilação de dados realizada no Brasil. Com o intuito de incluir essa fonte de observação na base de dados utilizada na assimilação do CPTEC/INPE e avaliar o impacto da mesma na melhoria do desempenho do Modelo de Circulação Geral Atmosférica, foi realizado um experimento para os meses de janeiro e agosto de 2014. Os resultados foram comparados com um experimento controle, onde tais dados não foram assimilados. Os resultados mostraram que a inclusão dos perfis de refratividade do MetOp-B impactou beneficamente na assimilação de uma maior quantidade de dados dos demais satélites em operação, COSMIC, TerraSAR-X e MetOp-A. No mês de agosto foram observados resultados mais proeminentes, pois o ganho em valores da raiz do erro quadrático médio foi maior que $40 \%$ nas variáveis de estado nas primeiras 24 h de previsão no Hemisfério Sul, variáveis essas diretamente relacionadas com os valores de refratividade. Além disso, os valores do coeficiente de correlação de anomalia sobre a América do Sul indicaram que a inclusão dos dados do MetOp-B impactou de forma indireta as componentes zonal e meridional do vento em $250 \mathrm{hPa}$, o que evidencia a importância de assimilar tais dados.
\end{abstract}

Palavras-chave: rádio ocultação GPS, assimilação de dados, MetOp-B.

\section{Impact of the Assimilation of Metop-B Satellite Refractivity Profiles in the Forecasts of the CPTEC/INPE During the Months of January and August 2014}

\begin{abstract}
Currently, there is an increase in the number of low orbit satellites dedicated to radio occultation of GPS signals. The MetOp-B is one of these new satellites, but it has not been explored in the data assimilation performed in Brazil. In order to include this source of observation in the database used in the assimilation of the CPTEC/INPE and evaluate its impact in the performance of the Atmospheric Global Circulation Model used operationally at the center, an experiment with data from January and August 2014 was executed. The results were compared with another experiment without assimilating those data, which showed that the inclusion of the MetOp-B refractivity profiles, has impacted beneficially the assimilation of more data from the other satellites in use, such as COSMIC, TerraSAR-X and MetOp-A. The most prominent results were observed in August, with root mean squared gain values greater than $40 \%$ in the state variables for the 24-h forecast over the Southern Hemisphere, variables that are directly related to the refractivity values. Beyond that, the anomaly correlation coefficient values over South America indicated that, adding the MetOp-B data, the zonal and meridional wind components at $250 \mathrm{hPa}$ were indirectly impacted, showing the importance of assimilate such data.
\end{abstract}

Keywords: GPS radio occultation, data assimilation, MetOp-B.

Autor de correspondência: Ivette Hernández Banos, ivette.banos@cptec.inpe.br. 


\section{Introdução}

A Previsão Numérica de Tempo (PNT) tem por objetivo a representação mais realista possível do estado futuro da atmosfera. Para isso se precisa de dois componentes fundamentais: um modelo matemático capaz de representar a dinâmica dos processos físicos que ocorrem na atmosfera e uma condição inicial baseada nas observações realizadas no mundo real. Essa condição inicial é produto de um processo denominado assimilação de dados, o qual combina previsão de curto prazo com as observações e busca uma solução chamada de análise que apresente um erro de mínima variância (Kalnay, 2003). A eficiência do processo é diretamente associada com a quantidade, qualidade e distribuição homogênea dos dados sobre todo o globo terrestre. Assim, a eficácia dos modelos de previsão é cada vez mais dependente de todo o conjunto dos sistemas de observações da atmosfera terrestre (Ucar, 2015). Atualmente com a melhoria dos instrumentos de medição, o desenvolvimento de novas metodologias, em especial as baseadas em satélites, e densificação das redes terrestres de observações, bem como das técnicas de processamento de dados, tem-se alcançado uma melhoria nas previsões de tempo e clima (Jin et al., 2014).

A técnica de rádio ocultação $(\mathrm{RO})$ terrestre permite a obtenção de medidas indiretas do estado termodinâmico da atmosfera. Esta técnica baseia-se na transmissão de ondas de rádio do sistema de navegação global por satélite (GNSS, acrônimo do inglês Global Navigation Satellite System) e a recepção desses sinais em um receptor a bordo de satélites de órbita baixa (LEO, acrônimo do inglês Low Earth Orbit) (Ucar, 2015). O sistema GNSS integra diversos outros sistemas, tais como o Sistema de Posicionamento Global (GPS, acrônimo do inglês Global Positioning System) dos Estados Unidos, o GALILEO da União Europeia e o GLONASS (acrônimo do inglês GLObal NAvigation Satellite System) da Rússia (Madry, 2015). Entre eles, o sistema mais utilizado na navegação moderna é o GPS. Esses satélites se encontram a uma altura sobre a superfície terrestre de aproximadamente $20.200 \mathrm{~km}$, enquanto que os satélites LEO orbitam a aproximadamente $800 \mathrm{~km}$ de altitude (Kursinski et al., 1997). Um único evento de ocultação dura de 1 a 3 minutos e é capaz de fornecer cerca de 4.000 medidas por perfil (Cucurull et al., 2007).

Os dados de RO por GPS (doravante RO-GPS) possuem especial importância para a PNT em aplicações operacionais, mais especificamente no processo de assimilação de dados, no qual dadas as suas particularidades figuram como uma importante fonte de informações da atmosfera. A qualidade dos mesmos bem como o seu impacto na melhoria das previsões tem sido amplamente estudados pelos grandes centros operacionais de PNT (e.g., Bevis et al. (1992), Eyre (1994), Cucurull et al. (2007), Aparicio e Deblonde (2008), Poli et al. (2009), Rennie (2010), Cucurull, Derber e Purser (2013), Bonavita (2014)). Entre os principais componentes da rede de observações obtidas por meio de satélites no Centro Europeu de Previsão de Tempo de Médio Prazo (ECMWF, acrônimo do inglês European Centre for Medium-range Weather Forecasting), esses dados ocupam uma posição de destaque, com uma contribuição de $6 \%$ na redução dos erros das previsões de curto prazo (Bonavita, 2014).

As medições de RO-GPS são minimamente afetadas por aerossóis, nuvens ou precipitação; são independentes da calibração de radiossondas e não se espera que tenham desvio nos instrumentos de medição nem viés nos seus resultados (Cucurull et al., 2007). Além disso, sua distribuição global é bastante uniforme tanto em oceanos quanto em continentes, com alta precisão e resolução vertical relativamente alta se comparada com as radiâncias de satélites por meio de sondagens do nadir (Kursinski et al., 1997). Porém, embora possuam uma cobertura global completa o comportamento é randômico, tornando-se difícil a obtenção de medidas de RO-GPS no mesmo ponto da atmosfera em horários diferentes. Isso é particularmente importante para a assimilação desses dados em uma região específica.

No Centro de Previsão de Tempo e Estudos Climáticos do Instituto Nacional de Pesquisas Espaciais (CPTEC/INPE), a assimilação dos perfis de RO-GPS tem demonstrado um impacto positivo na qualidade das previsões. De acordo com Sapucci et al. (2014), nota-se um aumento da correlação das anomalias previstas com as anomalias das análises e um ganho na extensão das previsões válidas de $24 \mathrm{~h}$. Nesse estudo foram realizados experimentos assimilando perfis atmosféricos de altura geopotencial e umidade, obtidos por meio dos perfis de refratividade utilizando dados da constelação COSMIC (acrônimo do inglês Constellation Observing System for Meteorology Ionosphere \& Climate). O sistema de assimilação utilizado nesse estudo foi o Sistema de Análise Estatística em Espaço Físico (PSAS, acrônimo do inglês Physical-space Statistical Analysis System), operacional no centro até 2013. Em Sapucci et al. (2015), usando o sistema de assimilação LETKF (acrônimo do inglês Local Ensemble Transform Kalman Filter) acoplado ao Modelo de Circulação Geral Atmosférica (MCGA) do CPTEC/INPE, foram assimilados perfis de refratividade provenientes da constelação COSMIC. Os resultados encontrados nesse estudo indicam impactos significativamente positivos sobre a América do Sul, em todas as variáveis avaliadas e durante quase todo o tempo de integração do modelo.

Visando incrementar o volume de dados a ser assimilados foi implementado no CPTEC/INPE o sistema G3DVar, entrando no ciclo de assimilação dados de perfis de refratividade dos satélites da constelação COSMIC, TerraSAR-X e MetOp-A. O último satélite do programa da Organização Europeia para Exploração de Satélites Meteorológicos (EUMETSAT, acrônimo do inglês European Organisation for the Exploitation of Meteorological Satellites), o satélite MetOp-B, substituiu o MetOp-A 
como o principal satélite meteorológico operacional em órbita polar da Europa. Ele torna-se uma opção para ampliação da base de dados de RO-GPS no CPTEC/INPE, pois ainda não foi explorado. $\mathrm{O}$ mesmo tem a bordo o instrumento Receptor GNSS de Sondagem Atmosférica (GRAS, acrônimo do inglês GNSS Receiver for Atmospheric Sounding), que foi o primeiro instrumento de obtenção de RO que fez uso dos satélites GPS para medir uma ocultação na ascendência de forma operacional.

$\mathrm{Na}$ literatura é comum encontrar trabalhos que afirmam que com o aumento da quantidade de dados provenientes de satélites, se obtém uma melhoria na qualidade da previsão no Hemisfério Sul (HS). Em Bonavita (2014), se confirma que isso pode ser atribuído à diferença na quantidade de observações convencionais, sendo que no HS se conta com aproximadamente $5 \%$ do total de observações de radiossondas e reportes de aeronaves disponíveis nos extratrópicos do Hemisfério Norte (HN). A partir dessa afirmação é plausível acreditar que, aumentando o número de observações assimiladas no HS espera-se encontrar impactos positivos nas previsões de tempo. Porém precisa ser definido especificamente quais regiões e variáveis meteorológicas são as mais impactadas.

Com a finalidade de demonstrar os benefícios advindos da inclusão dos dados de RO-GPS do MetOp-B na assimilação do CPTEC/INPE, o presente trabalho pretende avaliar o impacto dos mesmos na melhoria do desempenho do MCGA utilizado operacionalmente no CPTEC/INPE. Para atingir esse objetivo, na seção 2 é apresentada a técnica de rádio ocultação, uma revisão das missões de satélites equipados com receptores GPS e alguns dos resultados obtidos com assimilação de dados de RO-GPS. Na seção 3 são apresentados os detalhes da metodologia utilizada para a assimilação dos perfis de RO-GPS, assim como uma descrição dos dados empregados e os experimentos realizados. Na seção 4 são apresentados os resultados e a respectiva análise dos mesmos, enquanto que na seção 5 são apresentados os comentários finais.

\section{Técnica de Rádio Ocultação por GPS (RO-GPS)}

O fenômeno conhecido como ocultação óptica pode ser observado quando um corpo celeste deixa de ser visto em razão da sobreposição de outro corpo de interesse (Fjeldbo; Kliore; Eshleman, 1971). Esse fenômeno permite estudar diversas características dos corpos celestes envolvidos. Com o emprego dos sinais eletromagnéticos na exploração espacial surgiu o que hoje é conhecido de rádio ocultação, onde os sinais emitidos por satélites são ocultados em função da interferência de corpos celestes, porém quando isso ocorre é possível estudar a atmosfera desses corpos celestes. A RO é uma técnica que foi usada primeiramente para explorar as atmosferas e superfícies de outros planetas como foi em Marte em 1964, na missão
Mariner 4 realizada pela Administração Nacional do Espaço e da Aeronáutica (NASA, acrônimo do inglês $\mathrm{Na}$ tional Aeronautics and Space Administration) dos Estados Unidos (Eshleman, 1970; Fjeldboet al., 1971). Devido ao sucesso do uso da RO no estudo das atmosferas planetárias no sistema solar, e com o uso de sinais de rádio frequência para aplicações de navegação (sistema GPS), foi aplicada essa abordagem na exploração da própria atmosfera terrestre, o que é denominado de rádio ocultação GPS. No caso da RO-GPS isso acontece quando um receptor a bordo de um satélite LEO recebe o sinal emitido por um satélite GPS durante a sua ocultação pelo corpo terrestre em decorrência da variação do índice de refração atmosférico na trajetória de ambos os satélites. A atmosfera afeta as transmissões dos sinais durante essa ocultação fazendo com que as ondas viagem relativamente mais lentas do que no vácuo e em uma trajetória curva, ao invés de em linha reta (Bevis et al., 1992). Desde o ponto de vista da RO, na literatura a atmosfera é dividida em duas camadas de referência: a ionosfera, que corresponde à camada superior da atmosfera da Terra ionizada pela radiação solar, estendendo-se desde aproximadamente os $60 \mathrm{~km}$ até acima dos $1000 \mathrm{~km}$, e a atmosfera neutra, onde os componentes são eletricamente neutros e que se estende desde a superfície até próximo aos $60 \mathrm{~km}$ de altura (Jin et al., 2014). Os sinais são afetados pelos gradientes da densidade de elétrons na ionosfera e pela densidade e gradientes de vapor d'água na atmosfera neutra. Por conseguinte, através de perfis de refratividade obtidos é possível inferir medidas de pressão, pressão de vapor d'água e temperatura na atmosfera neutra, assim como também de densidade de elétrons na ionosfera.

\subsection{Geometria da rádio ocultação GPS}

Nos satélites LEO o que se observa durante uma ocultação é uma diferença na fase e amplitude dos sinais GPS recebidos. Essas diferenças são devidas, entre outros fatores, ao efeito Doppler em decorrência dos movimentos relativos de ambos os satélites, assim o excesso no efeito Doppler é calculado se as posições e as velocidades dos satélites são conhecidas. Podendo ser representado conforme é mostrado na Fig. 1, um esquema da geometria idealizada de uma ocultação instantânea entre os satélites GPS e LEO, com ênfase na área que compreende a atmosfera neutra.

A contribuição atmosférica no sinal pode ser caracterizada pelo ângulo de curvatura $\alpha$, referente à frequência observada do sinal GPS transmitido, ao ponto tangente do raio $r_{t}$, ao parâmetro de impacto $a$ e o conhecimento preciso da posição e velocidade dos satélites envolvidos $\left(v_{t}\right.$ e $\left.v_{r}\right)$. Assim, uma vez calculado o excesso no efeito Doppler é possível derivar o ângulo instantâneo de curvatura e, por conseguinte, a estrutura vertical do índice de refração atmosférica pode ser inferida se considerado todo o intervalo de tempo em que ocorre a ocultação. Posteriormente podem ser obtidos os perfis do conteúdo total de elétrons na 


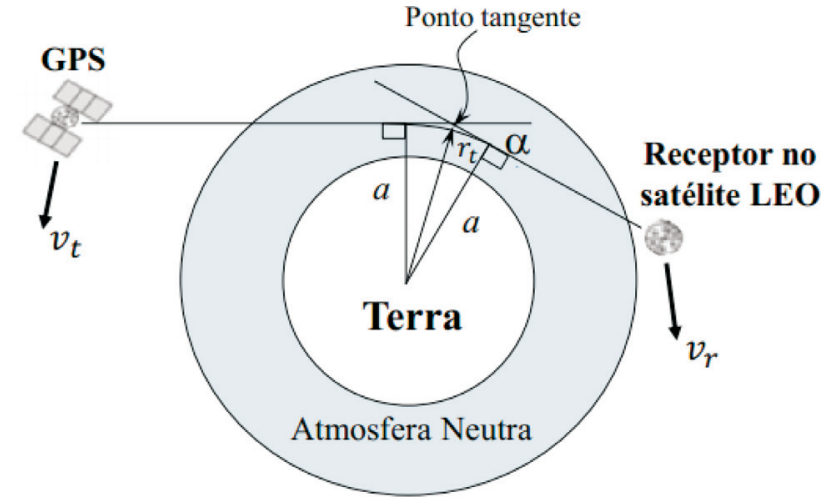

Figura 1 - Esquema ilustrativo da geometria de uma ocultação instantânea do sinal emitido pelo satélite GPS e recebido em um satélite LEO (Adaptado de Kuo et al. (2000) e Cucurull et al. (2007)).

ionosfera e da temperatura, pressão e pressão de vapor d'água na atmosfera neutra (Kursinski et al., 1997). Para a obtenção do índice de refração atmosférico a partir do ângulo de curvatura, comumente a transformada de Abel é usada, o qual só é possível assumindo que a simetria esférica local é satisfeita, ou seja, que a atmosfera não apresenta intensos gradientes horizontais em uma mesma camada. $\mathrm{Na}$ maioria dos casos pode-se assumir essa suposição (Syndergaard, 2000), mas se deve considerar que na atmosfera real essa suposição não ocorre podendo ser introduzidos erros significativos, em especial na umidade na baixa troposfera (Cucurull et al., 2007).

Na RO-GPS os dados são obtidos em vários níveis de processamento. As medidas da fase junto ao conhecimento preciso das posições e velocidades dos satélites GPS e LEO formam o conjunto de dados associados à atmosfera que pode ser considerado mais cru dentro da RO-GPS. Seguidamente são derivados os ângulos de curvatura referentes às frequências dos sinais GPS, a partir dos quais é possível obter perfis de refratividade em função da altura geométrica. Em um último nível de processamento se encontram os perfis de temperatura, pressão e pressão de vapor d'água, os que são inferidos a partir dos perfis de refratividade constituindo os dados mais processados, consequentemente nos que se esperam as maiores incertezas. Para a assimilação de dados é importante ressaltar que, com os dados em um estado mais cru, ou seja, menos processados, se produzem os melhores resultados, pois os diferentes estágios de processamento envolvem aproximações e, consequentemente, a inclusão de incertezas nos valores obtidos (Aparicio; Deblonde, 2008). No CPTEC/INPE, atualmente são assimilados somente os perfis de refratividade em função da altura geométrica.

\subsection{Missões espaciais equipadas com receptores GPS}

Com o lançamento da missão de prova de conceito GPS/MET (acrônimo do inglês Global Position System/Meteorology) em 1995 (Kursinski et al., 1997), foi comprovada a utilidade da técnica para o estudo da atmos- fera da Terra. A mesma constituiu a base para a criação de um sistema de análise de dados automatizada e a fabricação de uma nova geração de receptores para a RO mais sofisticados (Yunck et al., 2000), abrindo o caminho para o lançamento de muitas outras missões de satélites visando objetivos similares.

Entre as missões de satélites LEO para a recepção de dados de RO-GPS cita-se: o Orsted da Dinamarca lançado em 1999 e que ainda está em operação; o SunSat (acrônimo do inglês Stellenbosch University Satellite) da África do Sul, o qual operou de 1999 até 2001 (Eoportal, 2016); o CHAMP (acrônimo do inglês CHAllenging Minisatellite Payload), satélite alemão lançado em 2000 (Wickert; Galas; Beyerle, 2001) e que esteve em funcionamento até 2010; o SAC-C (acrônimo do espanhol Satélite de Aplicaciones Cientificas-C), satélite argentino também lançado em 2000 e que forneceu informação até o ano 2013. A missão GRACE (acrônimo do inglês Gravity Recovery and Climate Experiment), como parte de um esforço colaborativo envolvendo o Centro de Pesquisas Espaciais (CSR, acrônimo do inglês Center for Space Research) da Universidade do Texas, o Laboratório de Propulsão a Jato (JPL, acrônimo do inglês Jet Propulsion Laboratory) da NASA, o Centro Aeroespacial Alemão (DLR, acrônimo do alemão Deutsches Zentrum für Luft- und Raumfahrt) e o Centro de Pesquisa em Geociências (GFZ, acrônimo do alemão GeoForschungsZentrum), foi lançada em 2002 (Healy, 2007) e esteve operacional até o ano 2016. Da União Europeia, o primeiro do programa de satélites Meteorológicos Operacionais (MetOp), do Sistema Polar da EUMETSAT (EPS, acrônimo do inglês EUMETSAT Polar System), foi o MetOp-A lançado em 2006. O TerraSAR-X foi lançado em 2007 (Beyerle et al., 2011), como resultado de uma cooperação público-privada entre o DLR e a Companhia Europeia de Aeronáutica, Defesa e Espaço (EADS, acrônimo do inglês European Aeronautic Defence and Space Company) da Áustria. Ambos os satélites MetOp-A e TerraSAR-X estão atualmente em operação. A constelação de seis satélites FORMOSAT-3/COSMIC, do consórcio entre Taiwan e os Estados Unidos, foram lançados em 2006 (Anthes et al., 2008) dentre os quais cinco encontram-se atualmente em operação. $O$ satélite indiano OceanSat-2 da Organização de Pesquisas Espaciais da Índia (ISRO, acrônimo do inglês Indian Space Research Organization) foi lançado em setembro de 2009. Baseado no projeto da plataforma do SAC-C em junho de 2011 foi lançado o SAC-D/Aquarius, como parte de uma missão cooperativa internacional entre a Comissão Nacional de Atividades Espaciais da Argentina (CONAE) e a NASA. O satélite Megha-Tropiques foi lançado em outubro de 2011 como parte de uma missão cooperativa experimental entre a ISRO e o Centro Nacional de Estudos Espaciais da França (CNES, acrônimo do francês Centre National d'Études Spatiales). Na atualidade, os satélites OceanSat-2, SACD/Aquarius e Megha-Tropiques encontram-se operacio- 
nais. O segundo satélite do programa MetOp do EPS, o MetOp-B, foi lançado em 2012 (Yoon; Righetti, 2015) e está atualmente operacional. Todos esses satélites operaram entre 300-850 km de altitude sobre a superfície terrestre. A qualidade das medidas de RO tem sido avaliada ressaltando-se o impacto positivo na previsão e monitoramento do tempo e clima, assim como também a sua utilidade para pesquisas da ionosfera (e.g., Kursinski et al. (1997), Poli, Joiner e Kursinski (2002), Healy e Thépaut (2006), Healy (2007), Aparicio e Deblonde (2008), Buontempo, Jupp e Rennie (2008), Anthes et al. (2008), Cucurull e Derber (2008), Rennie (2008), Anthes (2011)).

\subsection{Rádio ocultação GPS usando o satélite MetOp-B}

O programa de satélites MetOp consiste de uma série de satélites meteorológicos LEO, em voo sucessivo desde 2006 e pretende continuar em funcionamento até 2020, quando planejam lançar a segunda geração dessa série, conhecidos como MetOp SG (acrônimo do inglês second generation). Os satélites MetOp são caracterizados por proverem dados para a PNT com melhor precisão e resolução espacial (Eoportal, 2016). O satélite MetOp-B foi lançado em setembro de 2012, possuindo uma altitude de $827 \mathrm{~km}$ e um período de 101 minutos. Espera-se que o terceiro satélite dessa geração, o MetOp-C, seja lançado em 2018 (Eumetsat, 2015).

O MetOp-B tem a bordo um conjunto de 11 instrumentos científicos, meteorológicos e climáticos, parte dos quais foram fornecidos pela Administração Nacional de Atmosfera e Oceano (NOAA, acrônimo do inglês National Oceanic and Atmospheric Administration) dos Estados Unidos, pelo CNES e pela Agência Espacial Europeia (ESA, acrônimo do inglês European Space Agency). Entre eles, se encontra uma nova geração de cinco instrumentos europeus que oferecem recursos aprimorados de detecção, citam-se: o GOME-2 (acrônimo do inglês Global Ozone Monitoring Experiment), o IASI (acrônimo do inglês Infrared Atmospheric Sounder Interferometer), o MHS (acrônimo do inglês Microwave Humidity Sounder), bem como o GRAS (Eumetsat, 2012).

O GRAS é um instrumento por meio do qual podem ser obtidos perfis de temperatura na troposfera e estratosfera com uma resolução vertical de $100 \mathrm{~m}$ na troposfera e $1,5 \mathrm{~km}$ na estratosfera, com precisão é de $1 \mathrm{~K}$ sobre uma faixa de altitude de 5 a $50 \mathrm{~km}$ aproximadamente. Além disso, o GRAS tem capacidade de medir a altura da tropopausa com uma precisão vertical melhor do que $1 \mathrm{~km}$. Esse instrumento permite observar mais de 500 ocultações por dia, com uma distribuição relativamente uniforme sobre todo o globo, o que é particularmente relevante para a PNT e o monitoramento do clima (Eoportal, 2016). A aplicação operacional mais importante para os dados produzidos pelo GRAS é a sua assimilação em modelos de PNT. A qualidade dos dados de refratividade provenientes do GRAS do
MetOp-B mostraram-se coerentes com os dados do GRAS do MetOp-A (Syndergaard, 2014).

\section{Materiais e Métodos}

O CPTEC/INPE recebe dados observacionais quase em tempo real de diversas fontes, sendo que a maioria desses dados advém do Sistema de Telecomunicação Global (GTS, acrônimo do inglês Global Telecommunication System), o qual é mantido pela Organização Meteorológica Mundial (WMO, acrônimo do inglês World Meteorological Organization). Nesta seção são apresentados os dados e os programas utilizados no desenvolvimento deste trabalho, bem como uma descrição dos experimentos realizados e da metodologia para a avaliação dos resultados obtidos.

\subsection{Dados disponíveis}

O período de estudo corresponde aos meses de janeiro e agosto de 2014. O custo computacional, espaço em disco bem como tempo necessário para a execução dos experimentos, foram os elementos fundamentais que limitaram a escolha de um período de estudo mais extenso. De tal forma, considerou-se adequada a escolha de dois meses de um ano em que foram representados os sistemas atmosféricos atuantes tanto no verão como no inverno austral. Os dados de RO-GPS assimilados foram os perfis de refratividade derivados dos receptores: Receptor GPS de Ocultação Integrado (IGOR, acrônimo do inglês Integrated GPS Occultation Receiver) a bordo dos satélites COSMIC e TerraSAR-X, e GRAS a bordo dos satélites MetOp-A e MetOp-B.

Os dados convencionais assimilados continham observações de vento zonal e meridional, temperatura, umidade específica e pressão à superfície, obtidas por meio de radiossondas, dropsondas, estações de superfície continental e marítima, sensores em aeronaves; balões pilotos e perfiladores de vento. Vetores de movimento atmosférico obtidos por imagens de satélites foram incluídos.

As observações de radiâncias assimiladas incluíram os dados: do MHS a bordo dos satélites NOAA-18 e -19 e do satélite MetOp-A e -B; do HIRS/4 (High-Resolution Infrared Radiation Sounders/4) a bordo do satélite NOAA -19, e do satélite MetOp-A e -B; do AIRS (Atmospheric Infrared Sounder) a bordo do satélite Aqua; do AMSU-A (Advanced Microwave Sounding Unit-A) a bordo dos satélites NOAA-15, -18 e -19, e do satélite MetOp-A e -B; e do IASI (Infrared Atmospheric Sounding Interferometer) também a bordo do satélite MetOp-A e B.

Todos esses dados são recebidos para sua assimilação no CPTEC/INPE via Protocolo de Transferência de Arquivo (FTP, acrônimo do inglês File Transfer Protocol).

\subsection{Programas disponíveis}

O sistema de assimilação e previsão utilizado neste estudo foi o G3DVar. Esse sistema utiliza o método varia- 
cional tridimensional implementado no sistema Interpolação Estatística em Ponto de Grade (GSI, acrônimo do inglês Gridpoint Statistical Interpolation) e acoplado ao MCGA do CPTEC/INPE. O GSI foi inicialmente desenvolvido pela NOAA e NCEP como um sistema de análise baseado no anterior sistema operacional do NCEP, que era o sistema Interpolação Estatística em Espaço Espectral (SSI, acrônimo do inglês Spectral Statistical Interpolation). No NCEP, o GSI foi implementado operacionalmente em maio de 2007, acoplado ao Sistema de Previsão Global (GFS, acrônimo do inglês Global Forecasting System). Ao assimilar dados de RO-GPS nesse sistema de assimilação, foi encontrada uma redução significativa da raiz do erro quadrático médio (RMSE, acrônimo do inglês root mean square error) estratosférico e do viés na temperatura para todas as latitudes (Anthes et al., 2008). Esse sistema de assimilação tem a capacidade de ser utilizado tanto para modelagens globais quanto para regionais. Uma descrição detalhada com relação à completa formulação empregada nesse sistema, assim como também as versões disponíveis podem ser obtidas em (Dtc, 2016).

Em janeiro de 2013, o GSI substituiu o PSAS como sendo o sistema oficial de análise no CPTEC/INPE. Em um estudo realizado pelo grupo de desenvolvimento em assimilação de dados deste centro, utilizando o G3DVar como sistema de assimilação, encontrou-se uma melhoria na qualidade das análises, com um aumento da capacidade de gerir um maior número de observações rotineiramente. Isso é devido à assimilação de radiâncias dos satélites de maneira direta (quantidade total de observações na ordem de $10^{6}$ ), ao invés da assimilação de radiâncias de maneira indireta, utilizando a técnica de recuperação (do inglês retrieval), o que limitava o sistema de assimilação anterior (na ordem de $10^{5}$ ). Esse resultado corresponde com o que foi afirmado em Eyre (1994), porém ao referir-se aos dados de RO-GPS, em que se afirma que a maneira mais promissora de utilizar esses dados é sua assimilação variacional em um modelo de circulação global atmosférica. Essa abordagem tem grandes vantagens em comparação com a reconstrução dos campos atmosféricos globais, dado que é possível assimilar uma quantidade de dados muito maior.

O MCGA do CPTEC/INPE, que compõe o G3DVar, realiza as suas previsões de tempo na resolução $\mathrm{T}_{q} 299 \mathrm{~L} 64$, o que representa uma resolução horizontal com truncamento triangular quadrático de 299 ondas em torno do globo e resolução vertical de 64 níveis. Sendo uma grade quadrática, o espaçamento de grade horizontal é em torno de $40 \mathrm{~km}$ no Equador $(900 \times 450$ pontos de grade horizontais). A coordenada vertical usada nesse modelo para escrever as equações do movimento é a coordenada sigma, definida por $\sigma=p / p s$, em que p se refere a um nível de pressão do modelo e ps à pressão na superfície. Neste estudo foi utilizada essa mesma configuração.

Com a finalidade de avaliar os resultados das simulações numéricas produzidas, foi utilizado o programa de avaliação denominado Sistema Comunitário de Avaliação de modelos Numéricos de Tempo e Clima (SCANTEC) em desenvolvimento pela divisão de modelagem e desenvolvimento do CPTEC/INPE. O SCANTEC baseia-se em que a avaliação dos produtos de Previsão Numérica de Tempo e Clima (PNTC) necessita de dois fatores fundamentais: o uso correto das observações e suas incertezas; e a escolha correta da métrica utilizada para cada tipo de variável analisada (Sapucci et al., 2010). Esse programa contém um módulo desenvolvido para o cálculo de métricas estatísticas básicas. Entende-se como métricas estatísticas básicas: o erro médio (ou viés) para medida de tendência; o RMSE e o desvio padrão para medidas de dispersão; e o coeficiente de correlação de anomalia (CCA), o qual é utilizado para avaliar o desempenho dos modelos de PNTC na representação das anomalias das previsões em comparação com as anomalias das análises, anomalias essas obtidas utilizando os campos climatológicos (Sapucci et al., 2010).

\subsection{Configuração dos experimentos}

Visando a inclusão de perfis de refratividade do MetOp-B no sistema de assimilação G3DVar do CPTEC/INPE foram configurados dois experimentos. O primeiro experimento correspondeu à assimilação de todos os dados disponíveis para entrar no ciclo de assimilação, digam-se, dados convencionais e não convencionais incluindo dados de perfis de refratividade de RO-GPS provenientes dos satélites da constelação COSMIC, do TerraSAR-X e do MetOp-A. Esse experimento foi realizado tendo em vista reproduzir o cenário mais próximo de como é realizada a assimilação de dados no CPTEC/INPE. Nesse, não são incluídos os dados de refratividade do MetOp-B sendo chamado de controle (identificado com a sigla CTL). O segundo experimento foi idêntico ao experimento controle, com exceção de que foram adicionadas as observações de refratividade provenientes do satélite MetOp-B, o qual doravante será identificado com a sigla MTB.

Vale destacar que particularmente a assimilação de perfis de refratividade, diferentemente da assimilação de ângulos de curvatura, não deve estender-se de forma confiável a alturas superiores a $30 \mathrm{~km}$, pois as sondagens de refratividade são fortemente ponderadas com climatologia na alta estratosfera durante o processo de recuperação do dado (Cucurull, 2010). Apesar dessa altura de $30 \mathrm{~km}$ estar bem abaixo da altura limite do modelo MCGA, que nessa configuração é de aproximadamente $56 \mathrm{~km}$, todos os dados de RO-GPS acima de $30 \mathrm{~km}$ foram rejeitados durante o procedimento de controle de qualidade dos mesmos. Além disso, em Cucurull et al. (2007) se afirma que a proporção de perfis de RO-GPS que penetram mais profundamente na baixa troposfera é relativamente pequena fundamentalmente devido a erros causados pelo forte gradiente de vapor d'água presente nessa região, pois é onde se concentra o 
maior conteúdo de umidade em toda a atmosfera. Por essa razão, para alturas abaixo de $5 \mathrm{~km}$, o sistema de assimilação está configurado para rejeitar as observações em que se comprove que o desvio padrão é uma vez maior ao previsto (Cucurull, 2010).

As análises foram realizadas em modo cíclico, no qual as previsões de $6 \mathrm{~h}$ do modelo são utilizadas como estimativa inicial para gerar a próxima análise ao assimilar todos os dados disponíveis em uma janela de $6 \mathrm{~h}$ em torno dos horários sinóticos, quais sejam: 0000, 0600, $1200 \mathrm{e}$ 1800 UTC. Dessa forma a janela de dados do ciclo realizado às 1200 UTC tem início às 0900 UTC e seu término as 1500 UTC, horário onde se inicia a janela de dados do ciclo das 1800 UTC, e assim sucessivamente para todos os dados disponíveis, como recomendado em Sapucci et al. (2014). Esse procedimento constitui o processo de assimilação de dados que é utilizado no CPTEC/INPE. Finalmente, por meio do SCANTEC foram calculadas as métricas estatísticas escolhidas.

\subsection{Metodologia de avaliação}

As variáveis escolhidas para realizar a avaliação dos resultados foram: conteúdo de água precipitável (AGPL), pressão ao nível médio do mar (PSNM), perfis de altura geopotencial (ZGEO), componentes zonal e meridional do vento (UVEL e VVEL, respectivamente) e umidade específica (UMES), assim como também as temperaturas sensível (TEMP) e virtual (VTMP). As variáveis ZGEO, UVEL, VVEL, TEMP foram avaliadas nos níveis 250, 500 e $850 \mathrm{hPa}$ e as variáveis UMES e VTMP foram avaliadas nos níveis 500,850 e $925 \mathrm{hPa}$.

Depois de realizados todos os experimentos e calculadas adequadamente as métricas estatísticas, foram avaliados os resultados encontrados. Primeiramente, para realizar uma adequada interpretação dos resultados da CCA, adotou-se como limiar para as previsões válidas aquelas que apresentaram valores de coeficiente acima de 0,6 , pois há consenso na literatura de que CCA igual a $60 \%$ corresponde ao limiar em que existe destreza sinótica nos padrões de grande escala. Essa medida varia de -1 a 1 , sendo positivamente orientada, o que implica que o valor perfeito é igual a 1, representando que há $100 \%$ de correlação entre as anomalias dos campos previstos e dos campos de análise com relação à climatologia. Para o caso dos valores de RMSE e o viés foram destacados aqueles em que tiveram os menores valores possíveis. Esses valores indicam em quais variáveis e regiões é mais notável a contribuição de cada informação, assim como também o tempo de integração do modelo em que é ampliada a validade da previsão.

Para auxiliar na interpretação dos resultados, outro coeficiente de interesse foi calculado como parte dessa metodologia. Esse coeficiente representa o ganho nos valores de RMSE, o qual se torna útil para apresentar quão importante foram os resultados nas previsões ao utilizar os dados de RO-GPS provenientes do MetOp-B com respeito ao experimento controle, o qual não inclui os dados de RO-GPS desse satélite. O ganho foi calculado por meio da Eq. (1):

$$
\text { Ganho }_{R M S E}=\frac{R M S E_{M T B}-R M S E_{C T L}}{R M S E_{\text {perfeito }}-R M S E_{C T L}} \times 100
$$

onde $R M S E_{M T B}$ e $R M S E_{C T L}$ representam os valores de RMSE dos experimentos incluindo as observações do MetOp-B e controle, respectivamente. Já $R M S E_{\text {perfeito }}$ representa o valor de RMSE em caso de previsões perfeitas, o que implica que o mesmo seja igual a 0 . Valores de ganho positivos indicam que o experimento adicionando as observações do MetOp-B beneficiaram as previsões do G3DVar com relação ao controle. Já valores negativos indicam que a adição dos dados degradou as previsões do G3DVar, quando comparados com o experimento controle.

Como parte da metodologia, para destacar os ganhos obtidos no mês e região de interesse, assim como em Anthes et al. (2008) foi calculada a mudança fracional (FC, acrônimo do inglês fractional change) referente ao RMSE das previsões realizadas com dados de RO-GPS do MetOp-B e o RMSE daquelas em que não foram assimilados esses dados. A FC é calculada por meio da Eq. (2):

$$
F C_{R M S E}=1-\frac{R M S E_{M T B}}{R M S E_{C T L}}
$$

Assim como o ganho, as medidas de FC são positivamente orientadas, com isso valores positivos indicam que o experimento adicionando as observações do MetOpB beneficiaram as previsões do G3DVar com relação ao controle e vice-versa. Posteriormente, são apresentados os resultados de FC na região onde o resultado foi mais benéfico, e foram analisadas as variáveis em que a assimilação dos dados do MetOp-B tiveram maiores impactos. Por último, foi calculada a diferença dos valores de RMSE entre ambos os experimentos realizados (RMSE $E_{C T L}$ $R M S E_{M T B}$ ), da mesma forma que as métricas anteriores, valores positivos indicam uma diminuição no RMSE e consequentemente uma melhoria no desempenho do modelo de previsão. Finalmente, foram apresentadas as áreas e analisadas as variáveis em que se obtiveram os resultados de diferenças mais promissores ao incluir os dados do MetOp-B na assimilação do CPTEC/INPE.

Nessa avaliação foram consideradas as regiões: Hemisfério Sul extratrópicos (HS), entre $80^{\circ} \mathrm{S}-20^{\circ} \mathrm{S}$; Hemisfério Norte extratrópicos $(\mathrm{HN})$, entre $80^{\circ} \mathrm{N}-20^{\circ} \mathrm{N}$; América do Sul (AS), entre $50^{\circ} \mathrm{S}-10^{\circ} \mathrm{N}$ e $80^{\circ} \mathrm{W}-30^{\circ} \mathrm{W}$; região Tropical (EQ), entre $20^{\circ} \mathrm{S}-20^{\circ} \mathrm{N}$; e a região global desde $80^{\circ} \mathrm{N}$ até $80^{\circ} \mathrm{S}$.

\section{Resultados e Discussão}

Um primeiro ponto que deve ser destacado na inclusão de um novo conjunto de dados é a forma em que o sistema de assimilação trata os dados dos demais conjuntos. 
No caso do presente estudo isso seria avaliar o impacto da inclusão dos perfis de refratividade do MetOp-B na assimilação de refratividades dos outros satélites. Para isso durante a execução dos experimentos foram quantificadas as observações assimiladas em cada ciclo de análise, os quais são apresentados na Fig. 2. Nessa figura os totais diários de dados de refratividade assimilados em cada experimento, durante agosto de 2014, são representados por barras verticais. A barra cinza escuro representa a quantidade de observações que foram assimiladas apenas do MetOp-B, e cinza claro e barras pretas os acumulados diários de observações provenientes dos demais satélites nos experimentos CTL e MTB, respectivamente. Os valores apresentados deixam evidente que o total de observações de refratividade assimiladas no experimento CTL é muito menor quando comparadas com a quantidade assimilada em MTB, o qual indica o primeiro impacto positivo da inclusão dos dados de RO-GPS do MetOp-B na entrada do processo de assimilação. No experimento controle observa-se que existe uma tendência à diminuição da quantidade de dados assimilados no período avaliado, sendo mais acentuado entre os dias 19 e 25 de agosto. Porém com a inclusão dos dados do MetOp-B constata-se claramente que essa tendência é minimizada mostrando-se um aumento com relação ao CTL, sendo esse aumento modesto no início e se intensificando com a evolução do processo cíclico no período. Isso é explicado pelo fato de que, diferente de outros sistemas de observação que avançam amostrando apenas uma região como as passagens de satélites de órbita polar, na RO-GPS são obtidas amostras bem distribuídas globalmente, embora com uma baixa resolução horizontal é possível obter informações confiáveis em regiões onde não se tem medidas a partir de outras fontes. Dessa forma, ao incluir as medidas de refratividade do MetOp-B, as diferenças entre o background e as observações são reduzidas globalmente com o avanço do processo cíclico da assimilação, possibilitando que mais observações sejam aceitas através dos diversos passos de assimilação envolvidos no processo. Dessa forma, observa-se um aumento gradual da quantidade de dados aceita dos outros satélites que na ausência do MetOp-B os mesmos (experimento CTL) foram rejeitados, confirmando o impacto positivo desses dados na assimilação das refratividades dos outros satélites. Em Cucurull et al. (2007) é reportado um resultado semelhante, o que demonstra um bom desempenho do algoritmo de minimização e a vantagem de ampliar a base de dados de RO-GPS para a assimilação operacional.

A fim de explorar em que níveis da atmosfera os dados de refratividade do MetOp-B exerceram um maior impacto, foram analisados os valores das observações menos os valores das análises $(\mathrm{OmA})$ e menos as previsões de curto prazo utilizadas como estimativas iniciais $(\mathrm{OmF})$. A

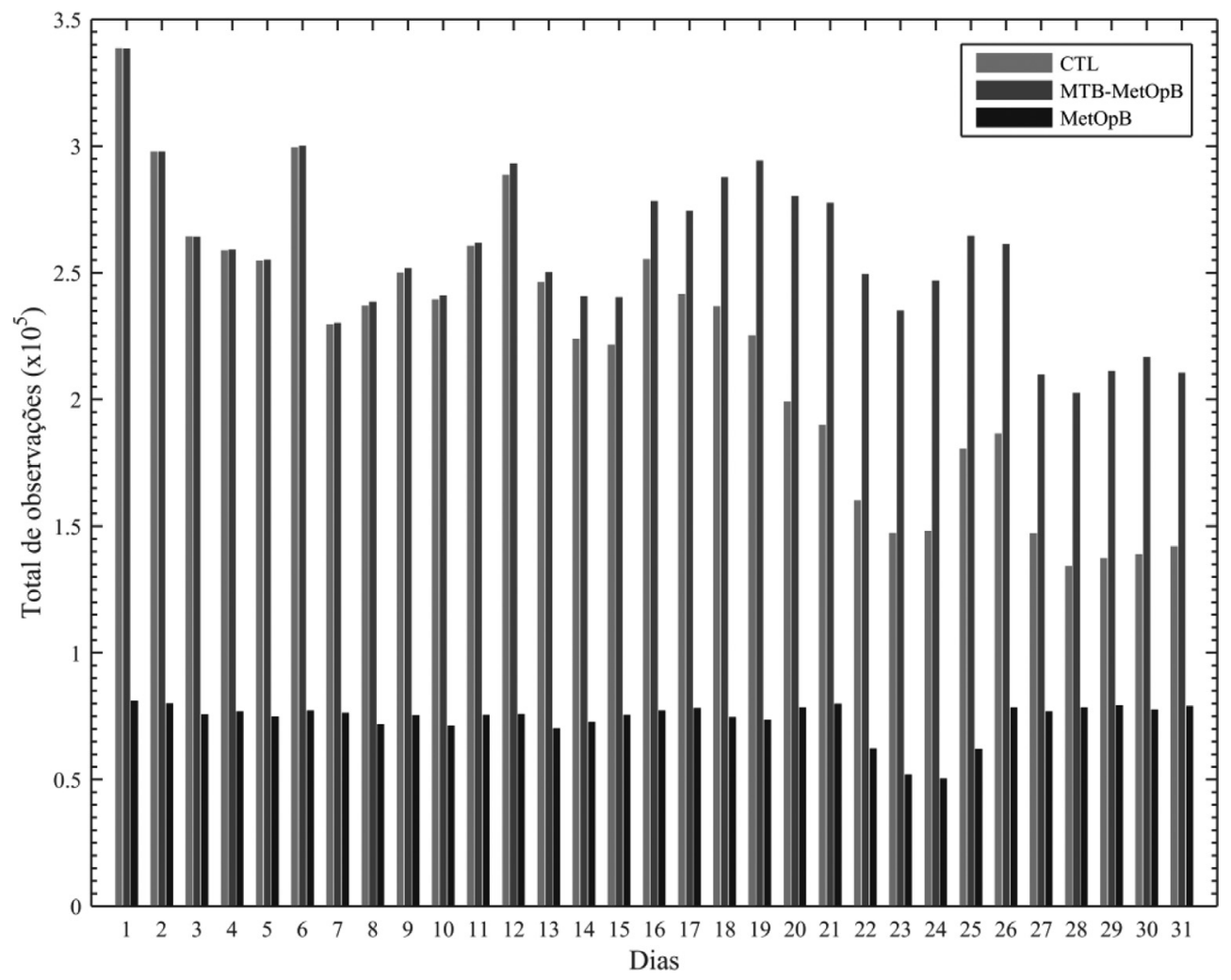

Figura 2 - Série temporal do acumulado diário de observações de RO-GPS utilizadas no experimento controle (coluna cinza claro), no experimento com MetOp-B subtraindo os dados assimilados desse satélite (coluna preta) e as observações utilizadas do MetOp-B (coluna cinza escuro) no G3DVar para o mês de agosto de 2014. 
Fig. 3 mostra esses valores através de diagramas de caixas separados em diferentes camadas atmosféricas organizadas em perfis verticais para os satélites da constelação COSMIC, TerraSAR-X, MetOp-A e MetOp-B. Em cada caixa, a marca central representa a mediana, as bordas da caixa representam os $25^{\circ}$ e $75^{\circ}$ percentis, os bigodes representam os dados extremos que não são considerados discrepantes nessa distribuição e as cruzes e círculos representam os valores discrepantes para $\mathrm{OmF}$ e OmA, respectivamente. Esse resultado é apresentado apenas para agosto de 2014 uma vez que janeiro de 2014 apresentou resultados similares. Na Fig. 3 pode ser observado que os valores médios e as incertezas observados do OmF foram reduzidos depois da assimilação ao observar os valores do OmA, os quais apresentam os valores médios menores (traço contínuo preto) e uma dispersão (representadas pelo tamanho das caixas) também menor que os valores apresentados no OmF. Isso permite afirmar que o processo de assimilação cumpriu sua função com relação a esses sistemas de observação, e permite verificar que o mesmo não apresentou problemas na minimização das incertezas nesse processo. Esse padrão é observado em todo o perfil atmosférico e também nos dados de todos os diferentes satélites. É notável que essas diferenças são maiores nas camadas mais inferiores da atmosfera diminuindo exponencialmente nas camadas mais elevadas, o qual é um resultado natural associado à própria física da refratividade atmosférica que apresenta esse mesmo padrão vertical. Observe que a escala na parte superior da figura teve que ser diminuída em um fator de 10 para tornar acessível às informações nesses níveis. Algo que merece destaque nessa figura é a maior quantidade de dados espúrios nessa análise com relação aos dados de refratividade dos satélites da constelação COSMIC, o qual pode estar associado com a qualidade dos resultados gerados uma vez que se trata dos satélites mais antigos em operação no momento.

Um outro ponto a ser destacado neste estudo são os ganhos produzidos na melhoria da qualidade das previsões obtidas com a inclusão das refratividades do MetOp-B, o que foi obtido com a comparação com os resultados obtidos
COSMIC

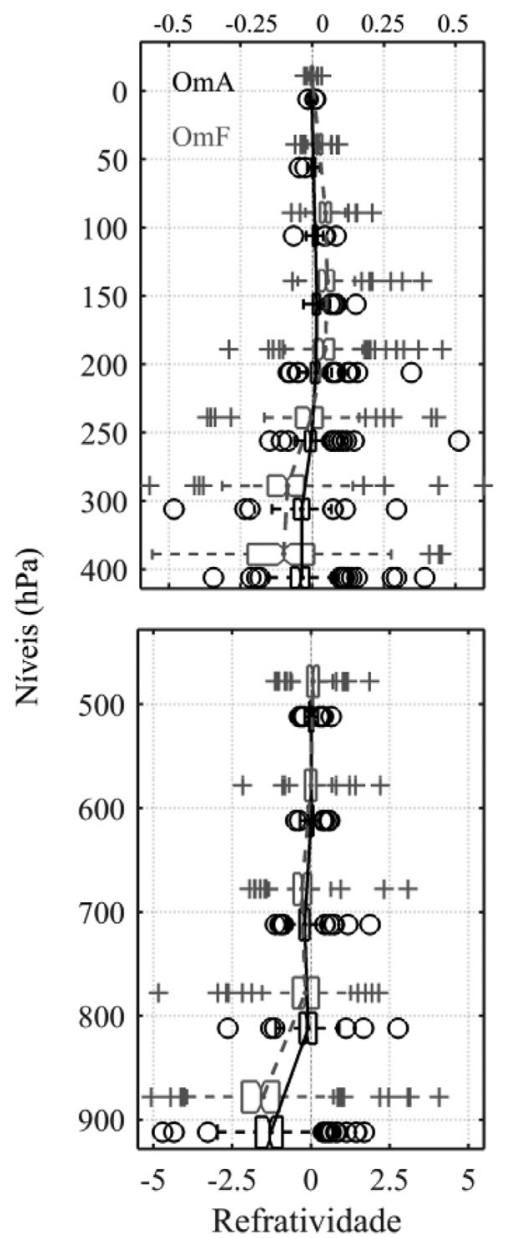

TerraSAR-X
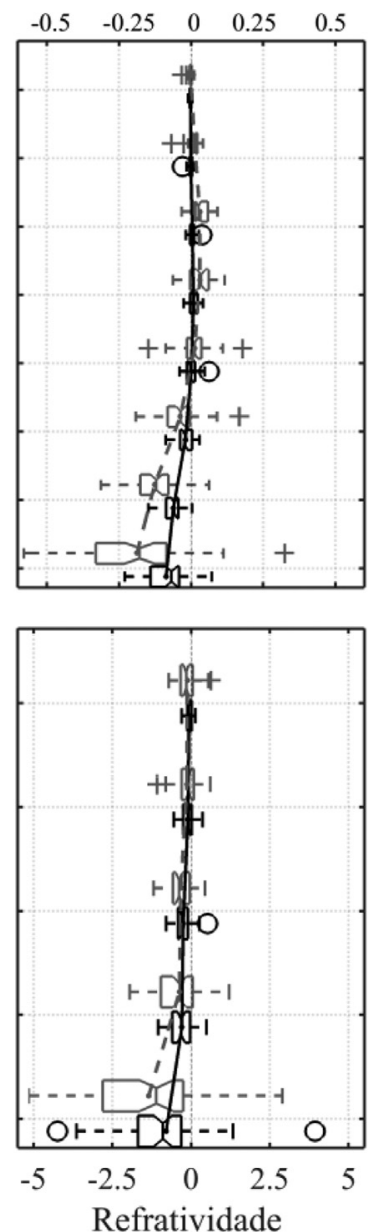

MetOp-A
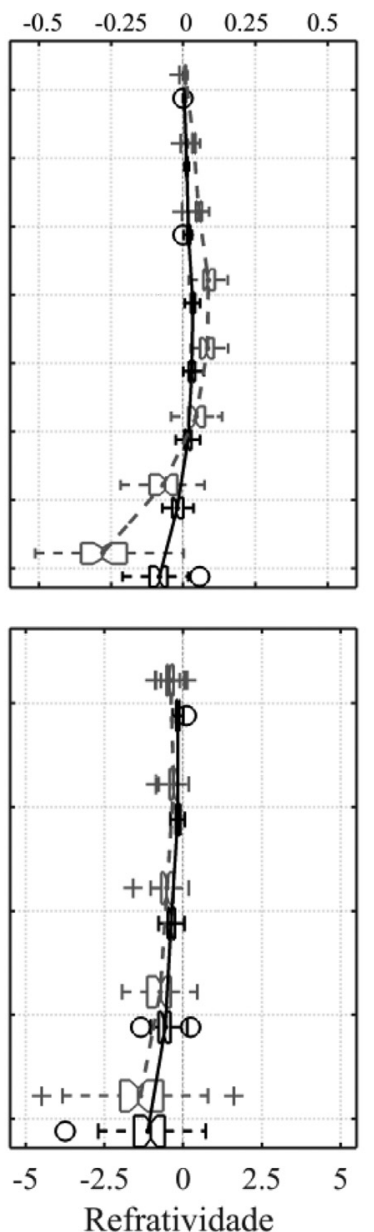

\section{MetOp-B}
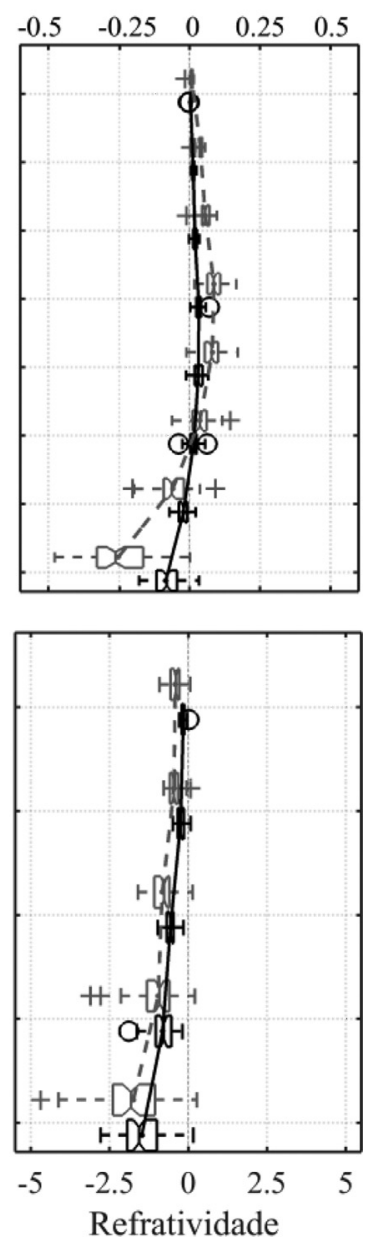

Figura 3 - Perfis verticais das diferenças de observações menos as análises (OmA, preto) e observações menos as estimativas iniciais (OmF, cinza) para refratividade em função dos níveis de pressão, médias entre as análises geradas as 0000 e 1200 UTC, para os satélites da constelação COSMIC, TerraSAR-X, MetOp-A e MetOp-B (da esquerda para a direita, respectivamente). 
no experimento controle. Em uma visão geral foi perceptível que entre os meses e regiões estudadas os resultados foram bem diferentes. Na Fig. 4 são apresentados os resultados de CCA obtidos para a variável ZGEO em $500 \mathrm{hPa}$, durante janeiro e agosto de 2014 nas regiões HN, EQ e HS (da esquerda para a direita, respectivamente). Observa-se claramente que os maiores impactos tanto positivos quanto negativos corresponderam ao mês de agosto, com uma extensão das previsões válidas para todo o período de integração nas áreas do HN e HS, sendo mais acentuados no HS em concordância ao apresentado em trabalhos como Cucurull et al. (2007) e Bonavita (2014). Destaca-se que a região do HS se encontra na estação de inverno, na qual segundo Cucurull et al. (2007) as observações são menos afetadas pela super-refração e heterogeneidades na refratividade horizontal, condições causadas fundamentalmente pelo gradiente de vapor d'água, sendo que ao adicionar os dados de refratividade do MetOp-B as previsões são esten- didas em 4\% desde as primeiras $24 \mathrm{~h}$ e mantendo-se válidas até o final do tempo de integração. Para o HN nesse mês, os resultados são importantes, pois embora se encontre em verão, ao adicionar esses dados nota-se uma melhoria a partir das $36 \mathrm{~h}$ com respeito ao experimento controle, com valores de CCA maiores a $70 \%$ até às $120 \mathrm{~h}$ de previsão. Por sua vez, na região Tropical observam-se os maiores valores de impacto negativos. O baixo desempenho desse sistema de observação nessa região já foi reportado em outros estudos, tais como Sapucci et al. (2014). A região EQ particularmente é caracterizada por possuir menor concentração de perfis de RO-GPS em relação às regiões dos extratrópicos, motivo pelo qual a constelação COSMIC-2 contará com satélites tanto de órbita polar como equatorial (Yen; Fong; Chang, 2012), de tal forma se espera que resultados mais promissores sejam obtidos nessa região após a operacionalização dessa constelação. No mês de ja-

\section{ZGEO-500 hPa Janeiro 2014}
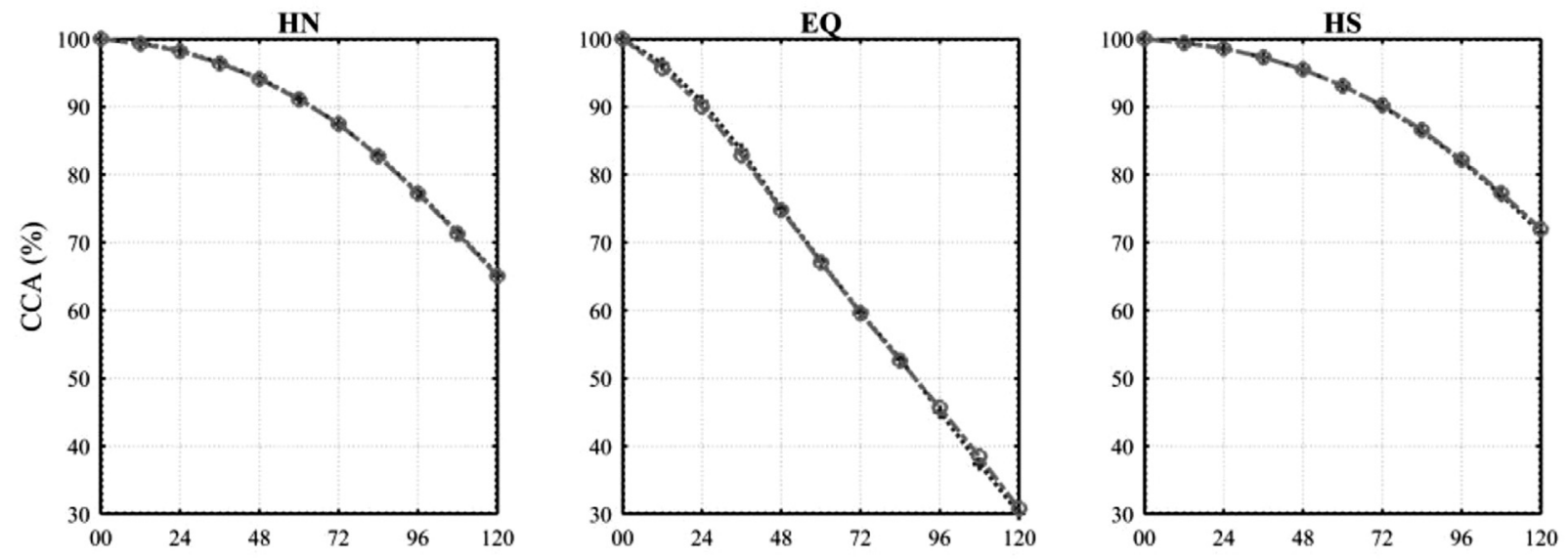

\section{ZGEO-500 hPa Agosto 2014}
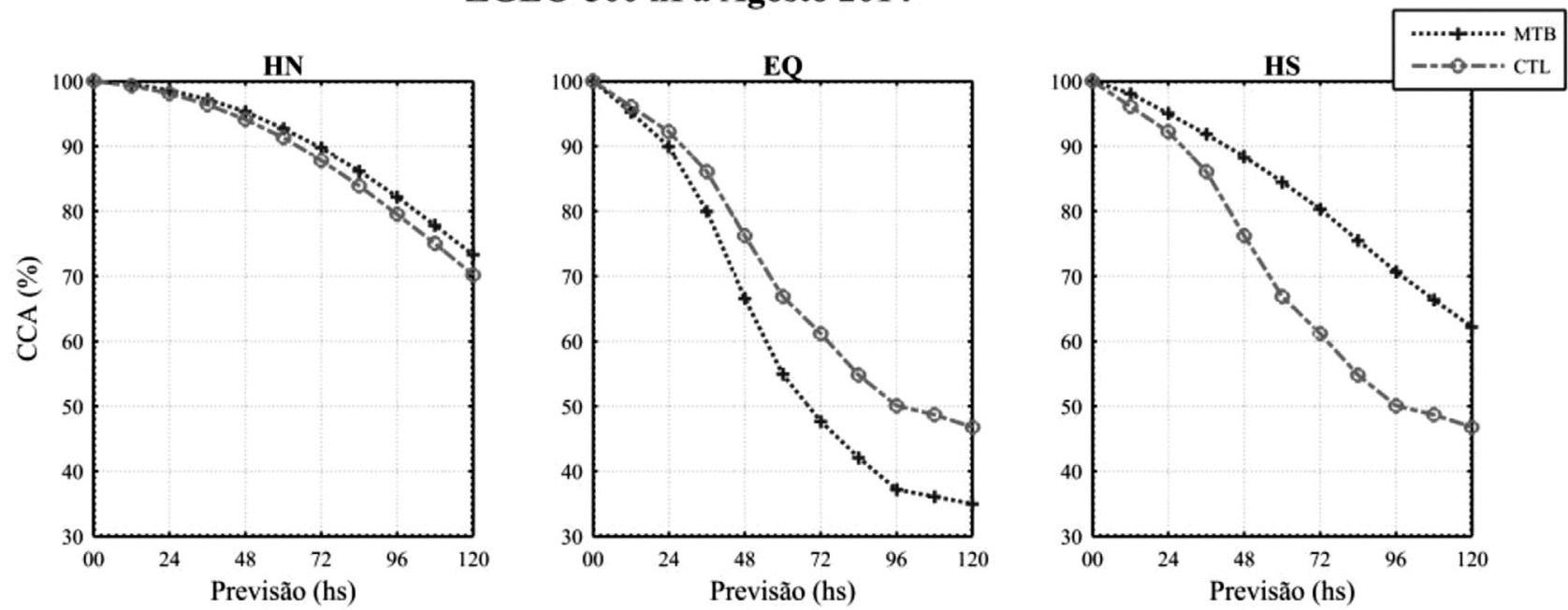

Figura 4 - Valores médios de coeficiente de correlação de anomalia (CCA) da altura geopotencial (ZGEO) em 500 hPa sobre o Hemisfério Norte extratrópicos (HN), Tropical (EQ) e Hemisfério Sul extratrópicos (HS), durante janeiro e agosto de 2014, para o experimento controle (curva com círculos cinzas) e para o experimento adicionando os dados do satélite MetOp-B (curva com cruzes pretas). 
neiro, esse impacto foi pouco importante nas três regiões apresentadas.

Para avaliar o impacto dos dados de RO-GPS do MetOp-B nas outras variáveis, o ganho percentual para diversas variáveis citadas na metodologia foram calculados. No mês de janeiro, embora os resultados fossem menos expressivos do que os observados em agosto, cabe ressaltar que no $\mathrm{HN}$ foi observado impactos positivos em praticamente todas as variáveis. A Fig. 5 mostra os valores do ganho percentual para o $\mathrm{HN}$, permitindo constatar que tais ganhos são expressivos e maiores nas previsões de mais curto prazo, o que indica que esses ganhos estão mais associados com a qualidade da análise do que a evolução do modelo. Há algumas variáveis que é observado perdas, mas nesses casos os valores são ínfimos. Embora os resultados não atinjam valores de ganhos muito elevados, são relevantes pelo fato de que nesse hemisfério a cobertura de observações convencionais é muito mais densa com relação às demais regiões do globo. Assim como em Bonavita (2014), em janeiro os resultados mais proeminentes da inclusão de dados de RO-GPS foram encontrados no HN.

Para o mês de agosto, os resultados no impacto da assimilação dos dados do MetOp-B em todas as variáveis avaliadas são mais expressivos no HS. Na Fig. 6 são apresentados os valores de ganho no RMSE, onde nota-se que nessa região os valores dos ganhos podem chegar até $60 \%$, como é o caso do ZGEO-250 e ZGEO-500. Observa-se que nessa região o impacto positivo da inclusão dessa fonte de dados aumenta com a integração do modelo, de forma que são menores e até há perdas em algumas variáveis em horários próximos à análise, mas os ganhos crescem substancialmente e as perdas diminuem ao se distanciarem da condição inicial. Nas previsões de $24 \mathrm{~h}$ as variáveis mais próximas da superfície e as associadas com a umidade apresentam perdas, mas com a integração do modelo essas perdas são praticamente anuladas e em alguns casos ganhos são observados depois de $72 \mathrm{~h}$. Mas na maioria das variáveis, fundamentalmente VTMP e TEMP, ZGEO e componentes U e V do vento, são observados valores de $60 \%$ tanto as 72 como às $120 \mathrm{~h}$ de integração. As perdas observadas nas variáveis de umidade podem ser devido à forma em como são analisados os campos de umidade dentro do sistema de assimilação. Neste estudo foi selecionada a umidade relativa normalizada como variável de controle da análise da umidade, pois é a variável utilizada operacionalmente no CPTEC, o qual é o ambiente que se pretende demonstrar o impacto dos dados aqui avaliados. Uma avaliação da escolha da variável de controle da umidade foi realizada, onde a pseudo-umidade relativa foi testada e comparada com a umidade relativa normalizada. Os resul-
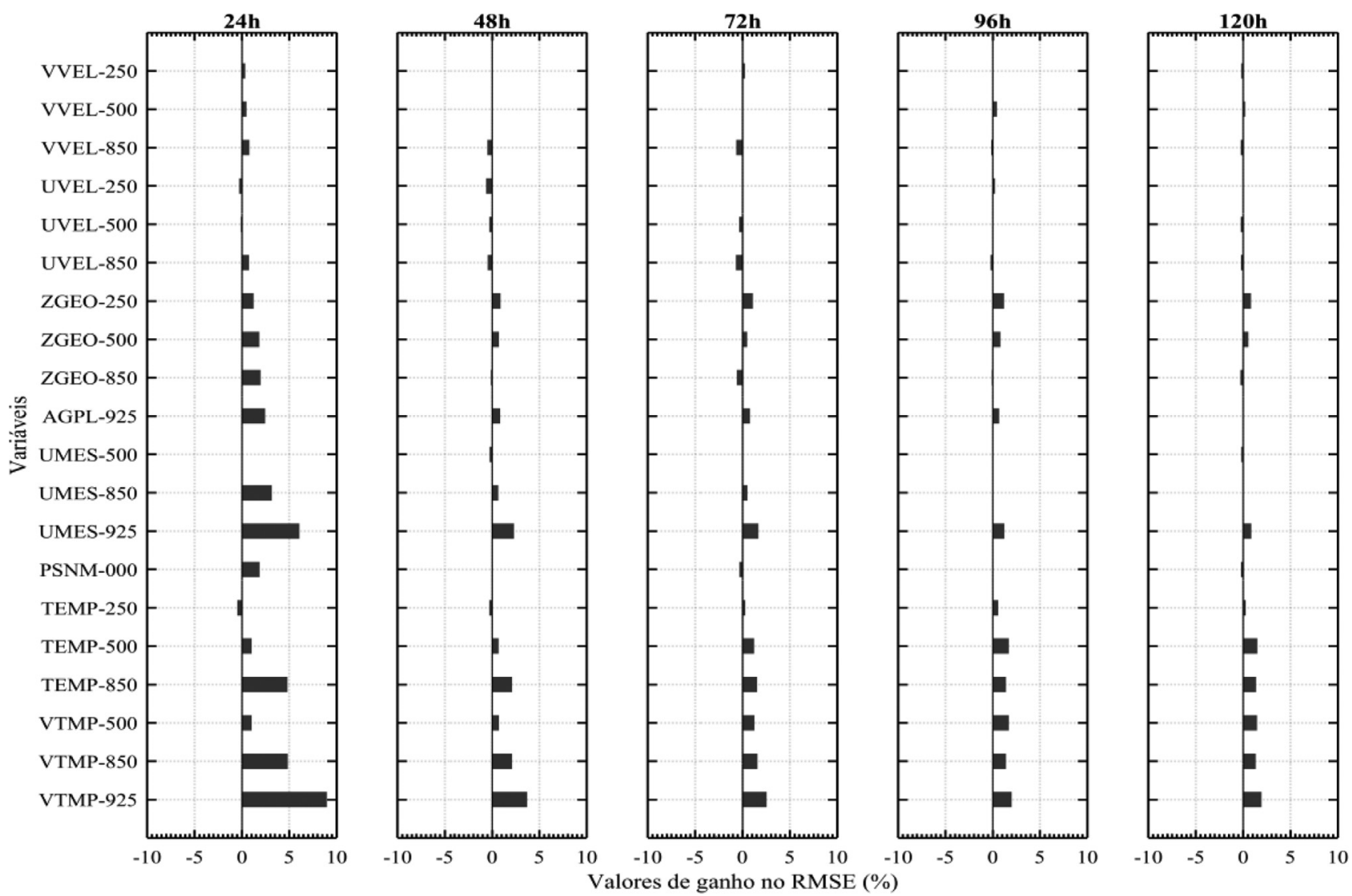

Figura 5 - Ganho percentual nos valores de RMSE em todas as variáveis avaliadas (representadas no eixo das ordenadas) para 24, 48, 72, 96 e 120 h de previsão (da esquerda para a direita, respectivamente), sobre o Hemisfério Norte extratrópicos durante janeiro de 2014. 

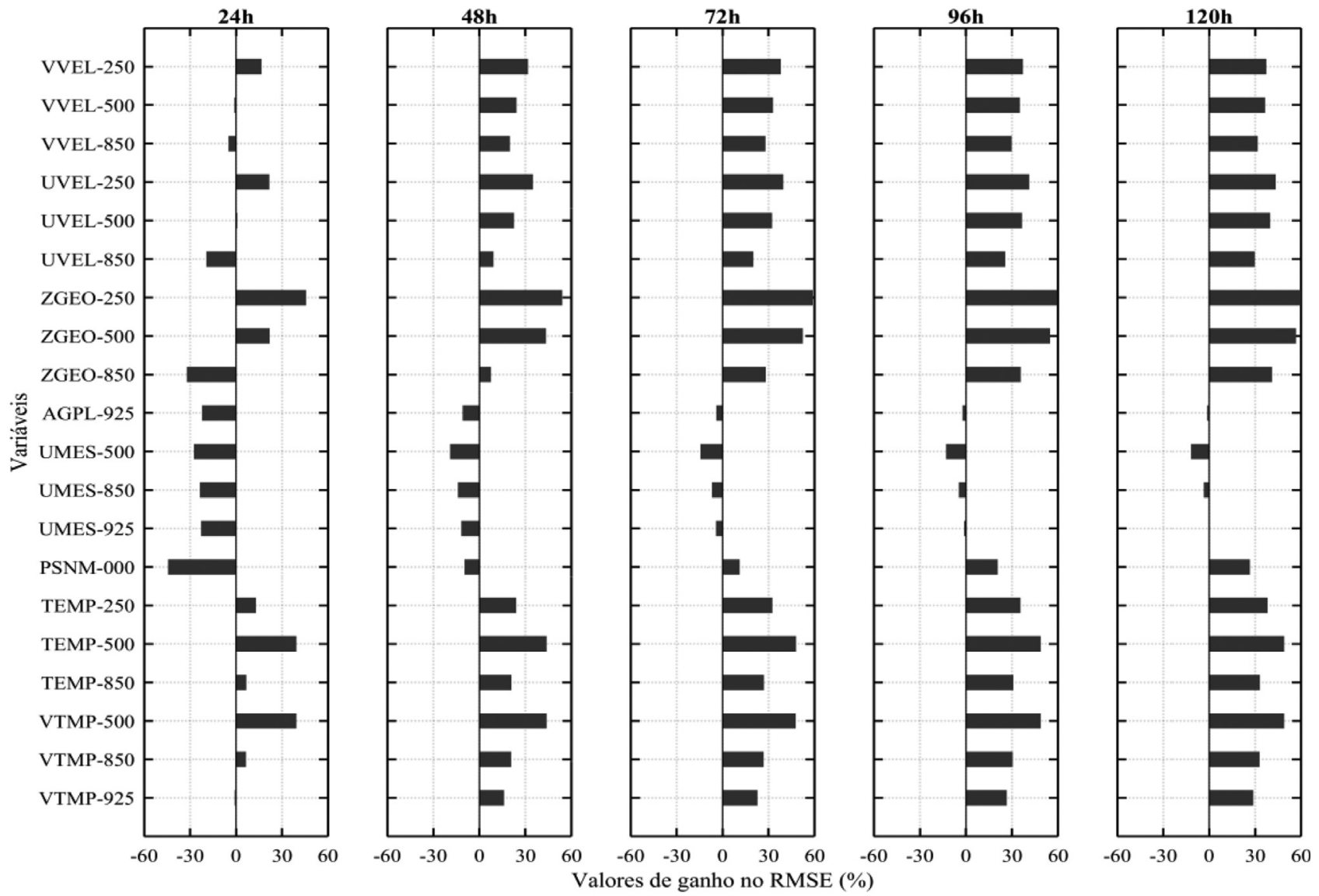

Figura 6 - Idem a Fig. 5, exceto que para o Hemisfério Sul extratrópicos durante agosto de 2014.

tados indicaram que a escolha da variável modifica significativamente o impacto dos dados, consequentemente estudos adicionais devem ser realizados para avaliar o impacto dos dados de refratividade quando outras variáveis de controle forem utilizadas (T.L. Campos, comunicação pessoal, 20 de Junho de 2016).

Como um dos focos principais do CPTEC é a previsão numérica de tempo visando o benefício da sociedade brasileira, foi realizada uma análise mais detalhada dos ganhos e perdas produzidos com ênfase na AS. Com base na análise sazonal realizada entre ambos os meses, foi escolhido o mês de agosto para apresentar esses resultados. Na Fig. 7 são apresentados os valores obtidos no cálculo de FC para a AS, nas variáveis ZGEO em $500 \mathrm{hPa}$, ZGEO e TEMP em $850 \mathrm{hPa}$ e PSNM, onde o eixo horizontal representa os horários de previsão. Pode ser observado que na ZGEO em $500 \mathrm{hPa}$ o impacto é positivo para todas as previsões, entretanto na ZGEO em $850 \mathrm{hPa}$ e na PSNM entorno das $24 \mathrm{~h}$ se produz um impacto positivo que se estende até o final do tempo de integração. O resultado encontrado para a variável PSNM demonstra o quanto os ganhos produzidos na AS contribuem aos ganhos encontrados na região do HS, pois nessa região foram observados ganhos na PSNM a partir das $72 \mathrm{~h}$ de previsão. Nota-se que para a TEMP em $850 \mathrm{hPa}$ os resultados se tornam positivos após as $94 \mathrm{~h}$ aproximadamente, porém mostram que com a inclusão de uma maior quantidade de dados de RO-GPS a tendência é de diminuição do RMSE com o tempo de integração. O comportamento das variáveis não apresentadas é em geral similar às aqui mostradas.

Em uma avaliação espacial sobre a AS, as previsões de $36 \mathrm{~h}$ foram escolhidas para representar as diferenças nos valores de RMSE entre ambos os experimentos para os impactos nas variáveis ZGEO em $500 \mathrm{hPa}$ e PSNM, as quais são mostradas na Fig. 8. O propósito fundamental dessa análise é observar em quais regiões específicas da AS se concentraram esses ganhos e perdas. Esse horário foi escolhido como recomendado em Sapucci et al. (2014), por serem as mais utilizadas em aplicações operacionais, pois representam as previsões de $12 \mathrm{~h}$ do dia seguinte a sua divulgação pelos meteorologistas. Melhorias na ZGEO em $500 \mathrm{hPa}$ são localizadas na metade sul da AS, com impactos positivos significativos localizados no sul do Brasil e norte do Uruguai, e na ponta sul da AS e oceanos adjacentes abrangendo a parte sul da Cordilheira dos Andes (CA). Parte da região nordeste do Brasil também é influenciada positivamente junto à porção noroeste da $\mathrm{AS}$ incluindo grande parte do norte da CA e do oceano adjacente. Algumas áreas isoladas entre o noroeste e o centro da AS possuem também impactos positivos. Por sua vez, nota-se 

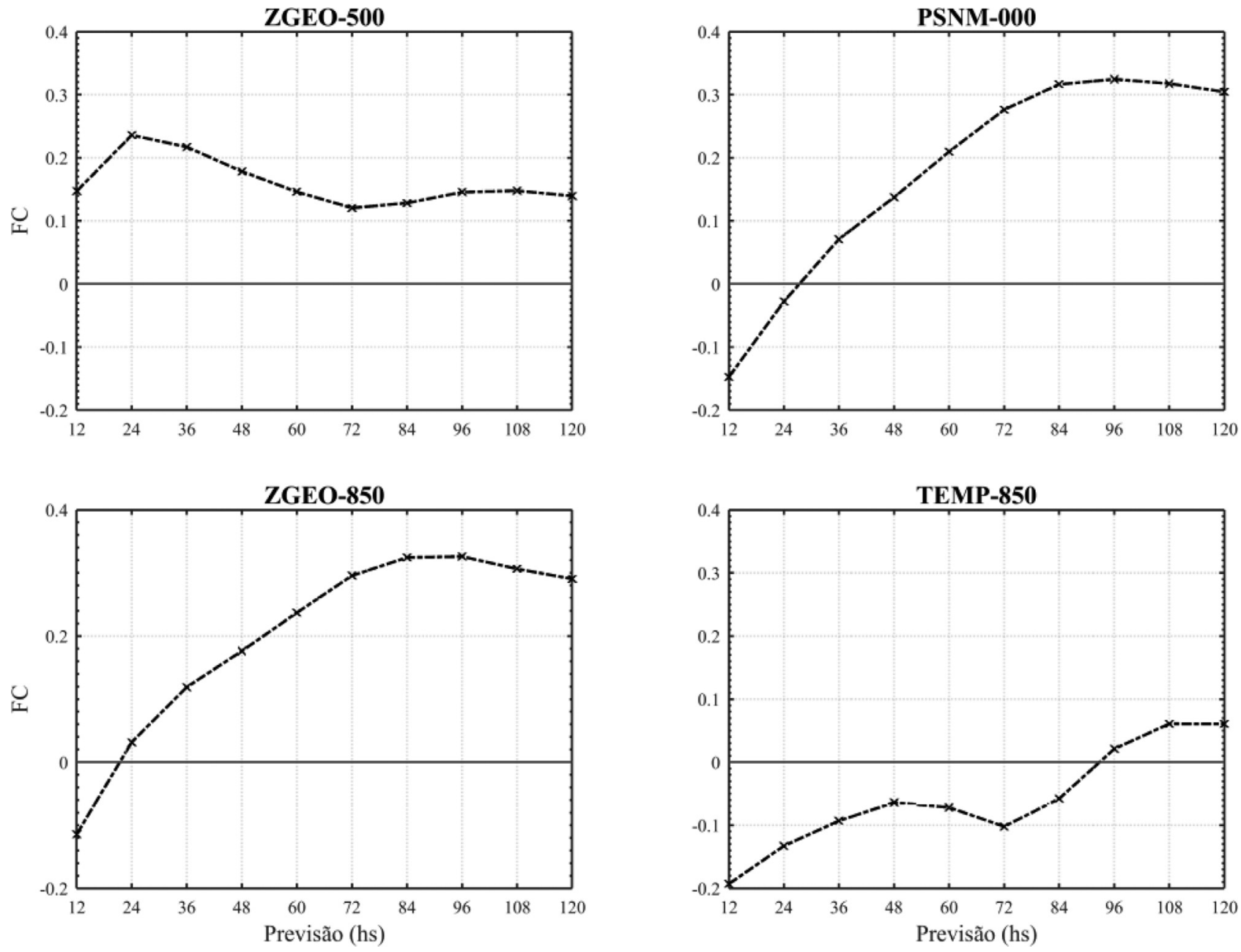

Figura 7 - Mudança fracional nos valores de RMSE para as variáveis altura geopotencial em 500 e 850, pressão ao nível médio do mar e temperatura em $850 \mathrm{hPa}$ em função do tempo de previsão, na América do Sul durante agosto de 2014.

que para a PSNM os maiores impactos positivos são encontrados entre os $45^{\circ} \mathrm{S}$ e $50^{\circ} \mathrm{S}$. Os resultados sobre a região nordeste do Brasil e o centro da AS apresentam uma melhoria abrangendo uma maior área. A porção noroeste da AS se mantém com impactos positivos para esta variável, porém diminuindo na horizontal, mas atingindo os $15^{\circ} \mathrm{S}$ de latitude. Parte dos oceanos adjacentes também são influenciadas positivamente ao incluir os perfis de refratividade do MetOp-B. Percebe-se que para esta variável os resultados com impactos positivos mostram-se menos abrangentes quanto para a ZGEO em $500 \mathrm{hPa}$. Da mesma forma, pode ser observado que uma área de impacto negativo é localizada na porção central e metade sul da CA, resultado pode estar relacionado com condições de super-refração nos sinais nessa região o que termina degradando a previsão. A super-refração constitui uma das principais fontes de erros nos sinais GPS na baixa troposfera (Cucurull et al., 2007), embora, em Jin, Cardellach e Xie (2014) são referenciados vários estudos nos quais se afirma que usando o método Rádio Holográfico para a reconstrução dos perfis de refratividade, esses erros podem ser reduzidos signi- ficativamente, porém mais estudos focalizados nas condições de super-refração sobre a CA devem ser realizados.

Além do exposto, apresentam-se também os resultados em relação ao tempo de previsões válidas com base nos resultados dos CCA para a AS. Cabe destacar o comportamento das variáveis VTMP e TEMP em $500 \mathrm{hPa}$ e as componentes de vento zonal e meridional em $250 \mathrm{hPa}$, UVEL e VVEL respectivamente para todo o tempo de integração do modelo, o qual é representado graficamente na Fig. 9. Nessa é ressaltada a linha que corresponde com o $60 \%$ por ser o limiar proposto para as previsões válidas. $\mathrm{Na}$ figura é possível observar o ganho no CCA para cada tempo de previsão, sendo que para as $36 \mathrm{~h}$ nas variáveis UVEL e VVEL em $250 \mathrm{hPa}$ respectivamente, encontrou-se ganhos de 3,6\% e na VTMP em $500 \mathrm{hPa}$ foi superior a 3,5\% de ganho nas previsões quando comparado com as previsões sem utilizar os dados de RO-GPS do MetOp-B. A variável TEMP em $500 \mathrm{hPa}$, entretanto, apresentou 3,3\% de ganho. Com isso, de modo geral mostra-se que ao assimilar dados de refratividade do MetOp-B são impactados também indi- 

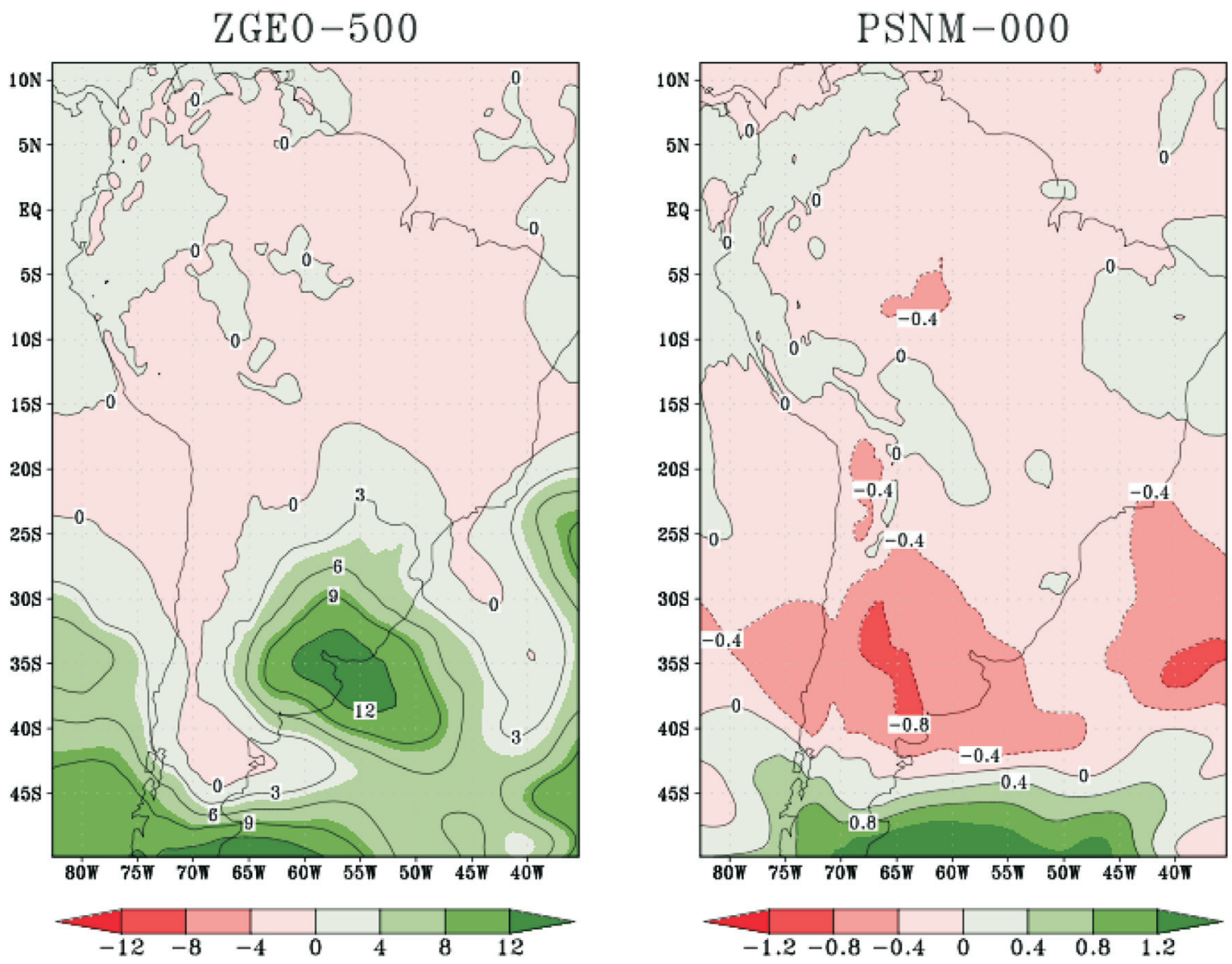

Figura 8 - Distribuição espacial da diferença nos valores de RMSE das previsões de 36 h entre o experimento controle e o experimento MTB, para as variáveis altura geopotencial em $500 \mathrm{hPa}$ (ZGEO-500, esquerda) e pressão ao nível médio do mar (PSNM-000, direita), na América do Sul durante agosto de 2014 .

retamente variáveis como UVEL e VVEL dadas as melhorias observadas. Resultado similar a esse foi encontrado em Rennie (2008). Outra variável que reflete essa mesma influência é a VTMP, revelando uma intensificação das melhorias obtidas na TEMP.

\section{Comentários Finais}

O presente artigo foi realizado com o propósito de avaliar o potencial do uso das observações de refratividade do MetOp-B no sistema de assimilação global do CPTEC/INPE e por meio dessa avaliação sugerir a inclusão dessa base de dados no Centro. Para isso, foram realizados dois experimentos usando o sistema de assimilação G3DVar. O primeiro experimento foi realizado com a configuração habitual da base de dados sem incluir os dados de RO-GPS do satélite MetOp-B. O segundo experimento foi idêntico ao primeiro com exceção de que foram adicionados os dados de RO-GPS do MetOp-B. Foi expressivamente perceptível que a entrada dos dados de refratividade dos outros satélites no sistema de assimilação, foi modificada ao incluir as refratividades do MetOp-B, pois foram aproveitadas uma quantidade maior das observa- ções, as mesmas que no experimento controle foram rejeitadas.

Entre os meses de agosto e janeiro analisados, observou-se que em agosto foram obtidos os maiores impactos nos valores de RMSE. Especificamente nesse mês, no HS foram observados os ganhos mais significativos no RMSE, atingindo $40 \%$ desde as primeiras $24 \mathrm{~h}$ de previsão. Foi encontrado, similar ao referenciado na literatura, o impacto indireto da assimilação de dados de RO-GPS em variáveis tais como as componentes zonal e meridional do vento, UVEL e VVEL, respectivamente e na VTMP. Particularmente, impacto negativo foi encontrado na variável UMES em todos os níveis e durante todo o período de previsão sendo minimizadas com a integração do modelo. Isso parece estar relacionado com a variável de controle dos campos de umidade no processo de assimilação, os quais merecem estudos mais detalhados. Sobre a AS observou-se que as variáveis com melhores resultados de FC foram ZGEO500 e a PSNM, as quais após 24 h produziram impactos positivos até o final do tempo de previsão, no entanto a primeira mostrou resultados mais abrangentes ao serem representadas as áreas em que se concentraram os valores mais relevantes. Do ponto de vista da avaliação das pre- 

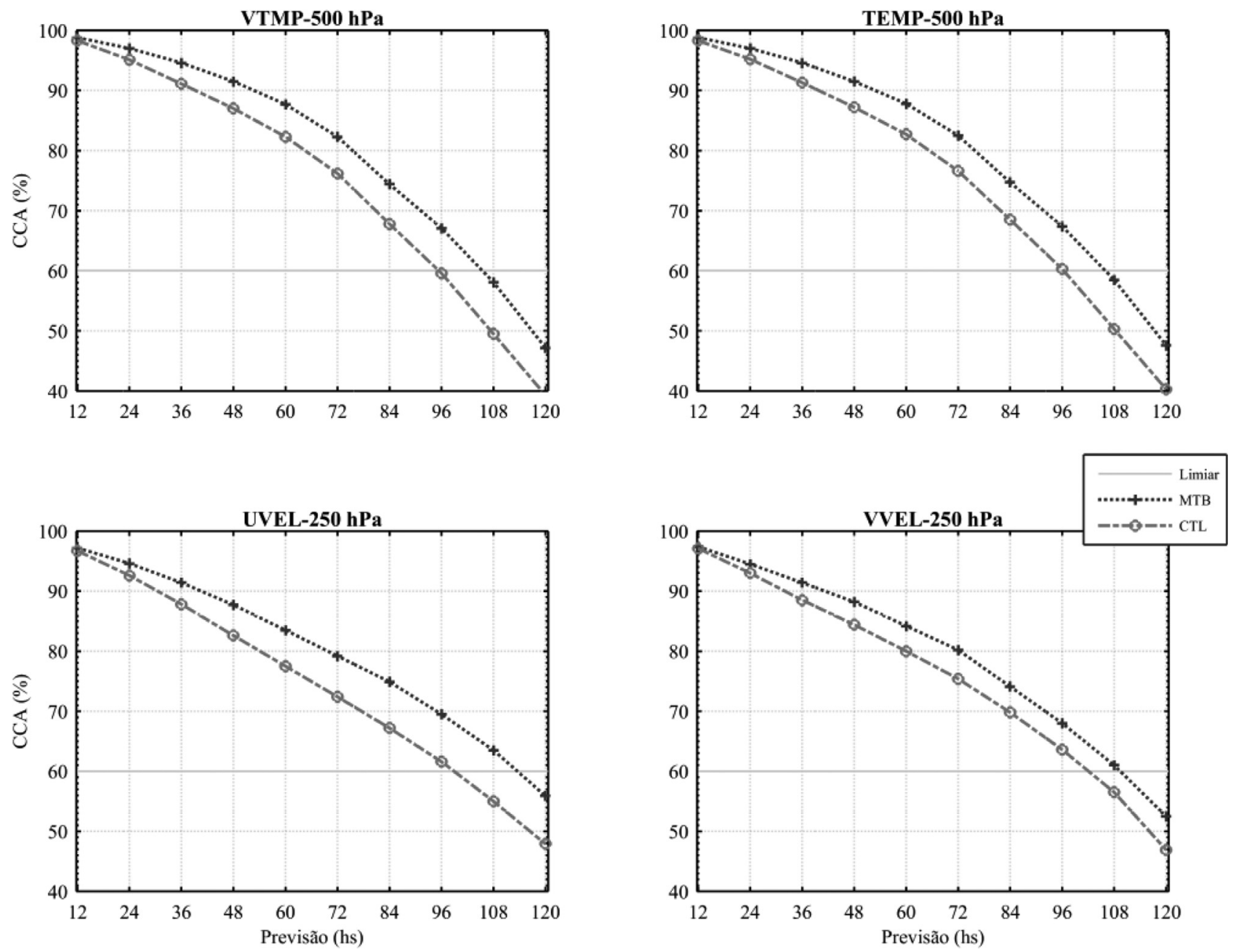

Figura 9 - Comportamento das previsões válidas das variáveis VTMP e TEMP em $500 \mathrm{hPa}$ e as componentes zonal e meridional do vento em $250 \mathrm{hPa}$, em relação a todo o tempo de integração, para agosto de 2014 sobre a América do Sul.

visões válidas, para as $36 \mathrm{~h}$ de previsão se destacam os resultados nas componentes zonal e meridional do vento, UVEL e VVEL, respectivamente, em $250 \mathrm{hPa}$, sendo que apresentaram um 3,6\% de ganho nas previsões que foram originadas das análises que utilizaram os dados de RO-GPS do MetOp-B quando comparado com as previsões sem utilizar esses dados, por sua vez, na VTMP em $500 \mathrm{hPa}$ mostraram uma melhoria em um 3,5\% e para a TEMP em $500 \mathrm{hPa}$, encontrou-se um ganho de 3,3\%. Por meio do exposto, conclui-se que os resultados evidenciaram a relevância da inclusão dos dados de RO-GPS do MetOp-B no sistema de assimilação acoplado ao MCGA do CPTEC/INPE na melhoria das previsões.

Com a ampliação da constelação de satélites LEO, o envolvimento dos demais sistemas de posicionamento e a evolução dos sistemas de assimilação de dados, com o refinamento da resolução espacial para aplicações de previsão de eventos extremos, essa linha de pesquisa está longe de ser exaurida e diversas funcionalidades, anuências outros aspectos associados à assimilação de dados de ROGPS deverão ser exploradas no futuro.

\section{Agradecimentos}

Os autores agradecem a todos que de forma direta ou indireta estiveram envolvidos na implementação da versão do G3DVAR no CPTEC, bem como aos colegas Dr. José Paulo Bonatti e Dr. Paulo Yoshio Kubota pela implementação do modelo MCGA do CPTEC. Agradecemos ao Conselho Nacional de Desenvolvimento Científico e Tecnológico $(\mathrm{CNPq})$ pelo apoio técnico e financeiro a essa pesquisa. Finalmente, os autores agradecem aos revisores anônimos, os que contribuíram para a melhoria do artigo.

\section{Referências}

ANTHES, R.; BERNHARDT, P.; CHEN, Y.; CUCURULL, L.; DYMOND, K.F et al. The COSMIC/FORMOSAT-3 mission: Early results. Bulletin of the American Meteorological Society, v. 89, n. 3, p. 313-333, 2008.

ANTHES, R.A. Exploring earth's atmosphere with radio occultation: Contributions to weather, climate and space weather. Atmospheric Measurement Techniques, v. 4, n. 6, p. 1077-1103, 2011. 
APARICIO, J.M.; DEBLONDE, G. Impact of the assimilation of CHAMP refractivity profiles on environment Canada global forecasts. Monthly Weather Review, v. 136, p. 257-275, 2008.

BEVIS, M.; BUSINGER, S.; HERRING, T.; ROCKEN, C.; ANTHES, R. et al. GPS meteorology: Remote sensing of atmospheric water vapor using the Global Positioning System. Journal of Geophysical Research, v. 97, n. D14, p. 15787-15801, 1992.

BEYERLE, G.; GRUNWALDT, L.; HEISE, S.; KöHLER, W.; KöNIG, R. et al. First results from the GPS atmosphere sounding experiment tor aboard the terrasar-x satellite. Atmospheric Chemistry and Physics, v. 11, n. 13, p. 66876699, 2011. ISSN 16807316.

BONAVITA, M. On some aspects of the impact of GPSRO observations in global numerical weather prediction. Quarterly Journal of the Royal Meteorological Society, n. October, p. 2546-2562, 2014.

BUONTEMPO, C.; JUPP, A.; RENNIE, M. Operational NWP assimilation of GPS radio occultation data. Atmospheric Science Letters, John Wiley \& Sons, Ltd., v. 9, n. 3, p. 129133, 2008.

CUCURULL, L. Improvement in the use of an operational constellation of GPS radio occultation receivers in weather forecasting. Weather and Forecasting, v. 25, n. 2, p. 749-767, 2010.

CUCURULL, L.; DERBER, J.C. Operational implementation of COSMIC observations into NCEP's global data assimilation system.Weather and Forecasting, v. 23, n. 4, p. 702-711, 2008.

CUCURULL, L.; DERBER, J.C.; PURSER, R.J. A bending angle forward operator for Global Positioning System Radio Occultation measurements. Journal of Geophysical Research-Atmospheres, v. 118, n. 1, p. 14-28, 2013.

CUCURULL, L.; DERBER, J.C.; TREADON, R.; PURSER, R.J. Assimilation of Global Positioning System Radio Occultation Observations into NCEP's Global Data Assimilation System. Monthly Weather Review, v. 135, n. 9, p. 31743193. 2007.

DTC. Community GSI Users Page. 2016. Disponível em: http://www.dtcenter.org/com-GSI/users/. Acesso em: 15.02.2016.

EOPORTAL.Satellite Missions Database. 2016. Disponível em: https://directory.eoportal.org/web/eoportal/satellite-mission. Acesso em: 13.02.2016.

ESHLEMAN, V.R. Atmospheres of Mars and Venus: A Review of Mariner 4 and 5 and Venera 4 Experiments. Radio Science, v. 5, n. 2, p. 325-332, 1970

EUMETSAT. Keeping a closer eye on weather and climate. 2012. BROCHURE PRG.02, v.1. Disponível em: http://www.eumetsat.int. Acesso em: 9.11.2015.

EUMETSAT. Metop. 2015. Disponível em: http://www.eumetsat.int/website/home/Satellites/CurrentSatellites/Metop/index.html. Acesso em: 9.11.2015.

EYRE, J.R. Assimilation of Radio Occultation measurements into a numerical weather prediction system. [S.1.], 1994. Technical Memorandum, n. 199. Disponível em: http://www.ecmwf.int/publications/PPTviaSimulatedAnnealing.pdf. Acesso em: 17.11.2015.
FJELDBO, G.; KLIORE, A.J.; ESHLEMAN, V.R. The neutral atmosphere of Venus as studied with the Mariner $\mathrm{V}$ radio occultation experiments. The Astronomical Journal, v. 76, n. 2, 1971.

HEALY, S.B. Assimilating GPS radio occultation measurements with two-dimensional bending angle observation operators. Quarterly Journal of the Royal Meteorological Society, v. 133, n. July, p. 937-948, 2007.

HEALY, S.B.; THÉPAUT, J.N. Assimilation experiments with CHAMP GPS radio occultation measurements. Quarterly Journal of the Royal Meteorological Society, v. 132, p. 605-623, 2006.

JIN, S.; CARDELLACH, E.; XIE, F. GNSS Remote Sensing: Theory, Methods and Applications. 1. ed. Springer Netherlands, 2014. (Remote Sensing and Digital Image Processing, v. 19).

KALNAY, E. Atmospheric modeling, data assimilation, and predictability. Cambridge University Press, United Kingdom, 2003. 341 p. ISBN 9780521796293.

KUO, Y.-H., SOKOLOVSKIY, S.; ANTHES, R.A.; VANDENBERGHE, F. Assimilation of GPS radio occultation data for numerical weather prediction. Terrestrial Atmospheric and Oceanic Sciences, v. 11, p. 157-186, 2000.

KURSINSKI, E.R.; HAJJ, G.; SCHOFIELD, J.T.; LINFIELD, R.P.; HARDY, K.R. Observing earth's atmosphere with radio occultation measurements using the Global Positioning System. Journal of Geophysical Research, v. 102, n. D19, p. 23429-23465, 1997.

MADRY, S. Global Navigation Satellite Systems and Their Applications. 1. ed. Springer-Verlag New York, 2015.

POLI, P.; JOINER, J.; KURSINSKI, E.R. 1DVAR analysis of temperature and humidity using GPS radio occultation refractivity data.Journal of Geophysical Research: Atmospheres, v. 107, n. D20, p. ACL 14-1-ACL 14-20, 2002.

POLI, P.; MOLL, P.; PUECH, D.; RABIER, F.; HEALY, S. Quality control, error analysis, and impact assessment of FORMOSAT-3/COSMIC in numerical weather prediction. Terrestrial, Atmospheric and Oceanic Sciences, v. 20, n. 1, p. 101-113, 2009.

RENNIE, M.P. The assimilation of GPS Radio Occultation measurements at the MetOffice. In: ECMWF/GRAS-SAF Workshop on Applications of GPSRO Measurements, 16-18 June 2008.

RENNIE, M.P. The impact of GPS radio occultation assimilation at the MetOffice. Quarterly Journal of the Royal Meteorological Society, v. 136, n. 646, p. 116-131, 2010.

SAPUCCI, L.F.; BASTARZ, C.F.; CERQUEIRA F.; AVANÇO, L.A.; HERDIES, D.L. Impacto de perfis de rádio ocultação GNSS na qualidade das previsões de tempo do CPTEC/INPE. Revista Brasileira de Meteorologia, v. 29, n. 4, p. 551-567, 2014.

SAPUCCI, L.F.; DINIZ, F.L.R.; BASTARZ, C.F.; AVANÇO, L.A. Inclusion of Global Navigation Satellite System radio occultation data into Center for Weather Forecast and Climate Studies Local Ensemble Transform Kalman Filter (LETKF) using the Radio Occultation Processing Package as an observation operator. Meteorological Applications, v. 23 , p. $328-338.2016$.

SAPUCCI, L.F.; GONÇALVES, L.G.G; MATTOS, J.G.Z; BASTARZ, C.F.; SANTOS, A.F. Conselho nacional de desenvolvimento científico e tecnológico. Investigação de 
métricas estatísticas e implementação no sistema comunitário de avaliação de modelos numéricos de previsão de tempo e clima - SCAMTEC. In: Projeto de pesquisa CNPq - Universal 2010. Julho. [S.1.: s.n.], 2010. p. 27.

SYNDERGAARD, S. On the ionosphere calibration in GPS radio occultation measurements. Radio Science, v. 35, n. 3, p. 865-883, 2000.

SYNDERGAARD, S. Near Real-Time Level 2a Refractivity Profiles: Metop-A (GRM-01, NRPMEA) and Metop-B (GRM-40, NRPMEB), 2014. SAF/ROM/DMI/RQ/REP/001. Disponível em: http://www.romsaf.org.

UCAR. GPS Radio Occultation-Atmospheric Profiling with Global Navigation Satellite Systems (GNSS). 2015. Disponível em: http://www.cosmic.ucar.edu/ro.html. Acesso em: 24.11.2015.
WICKERT, J.; GALAS, R.; BEYERLE, G. GPS ground station data for CHAMP radio occultation measurements. Physics and Chemistry of the Earth, v. 26, p. 503-511, 2001.

YEN, N.L.; FONG, C.-J.; CHANG, G.-S. Approaching the First Global Radio Occultation Operational Mission Using Constellation LEO Satellites. In: EUMETSAT Meteorological Satellite Conference, At Sopot, Poland, Sep 27-30, 2012.

YOON, Y.T.; RIGHETTI, P.L. Precise Calibration of MultiSegment Maneuvers for EUMETSAT Polar System Operations Planning. In: Proceedings of the $25^{\text {th }}$ International Symposium on Space Flight Dynamics, Munich, Germany, October 19-23, 2015. p. 19-23. Disponível em: http://issfd.org/2015/files/downloads/papers/061_Yoon.pdf.

YUNCK, T.P.; LIU, C.-H.; WARE, R. A history of GPS sounding. Terrestrial, Atmospheric and Oceanic Science, v. 11, n. 1, p. 1-20, 2000.

This is an Open Access article distributed under the terms of the Creative Commons Attribution Non-Commercial License which permits unrestricted non-commercial use, distribution, and reproduction in any medium provided the original work is properly cited. 